Article

\title{
Intrinsic Angiogenic Potential and Migration Capacity of Human Mesenchymal Stromal Cells Derived from Menstrual Blood and Bone Marrow
}

\author{
Rosana de Almeida Santos ${ }^{1}$, Karina Dutra Asensi ${ }^{1}{ }^{\circledR}$, Julia Helena Oliveira de Barros ${ }^{1}($, \\ Rafael Campos Silva de Menezes ${ }^{1}$, Ingrid Rosenburg Cordeiro ${ }^{2,3}{ }^{(D)}$, \\ José Marques de Brito Neto ${ }^{2}$, Tais Hanae Kasai-Brunswick ${ }^{1,4,5}$ \\ and Regina Coeli dos Santos Goldenberg $1,5, *$ (i)
}

1 Carlos Chagas Filho Institute of Biophysics, Federal University of Rio de Janeiro, Rio de Janeiro 21941902, Brazil; rosana_almeida@ufrj.br (R.d.A.S.); karina_asensi@biof.ufrj.br (K.D.A.); juliahelenadb@gmail.com (J.H.O.d.B.); rafael.camposrj@hotmail.com (R.C.S.d.M.); kasaitais@yahoo.com.br (T.H.K.-B.)

2 Institute of Biomedical Sciences, Federal University of Rio de Janeiro, Rio de Janeiro 21941902, Brazil; ingridrcordeiro@gmail.com (I.R.C.); brito@histo.ufrj.br (J.M.d.B.N.)

3 Department of Life Science and Technology, Tokyo Institute of Technology, Yokohama 2268501, Japan

4 National Center of Structural Biology and Bioimaging, Federal University of Rio de Janeiro, Rio de Janeiro 21941902, Brazil

5 National Institute of Science and Technology for Regenerative Medicine-REGENERA, Federal University of Rio de Janeiro, Rio de Janeiro 21941902, Brazil

* Correspondence: rcoeli@biof.ufrj.br

Received: 25 October 2020; Accepted: 10 December 2020; Published: 15 December 2020

\begin{abstract}
Several therapies are being developed to increase blood circulation in ischemic tissues. Despite bone marrow-derived mesenchymal stromal cells (bmMSC) are still the most studied, an interesting and less invasive MSC source is the menstrual blood, which has shown great angiogenic capabilities. Therefore, the aim of this study was to evaluate the angiogenic properties of menstrual blood-derived mesenchymal stromal cells (mbMSC) in vitro and in vivo and compared to bmMSC. MSC's intrinsic angiogenic capacity was assessed by sprouting and migration assays. mbMSC presented higher invasion and longer sprouts in 3D culture. Additionally, both MSC-spheroids showed cells expressing CD31. mbMSC and bmMSC were able to migrate after scratch wound in vitro, nonetheless, only mbMSC demonstrated ability to engraft in the chick embryo, migrating to perivascular, perineural, and chondrogenic regions. In order to study the paracrine effects, mbMSC and bmMSC conditioned mediums were capable of stimulating HUVEC's tube-like formation and migration. Both cells expressed VEGF-A and FGF2. Meanwhile, PDGF-B was expressed exclusively in mbMSC. Our results indicated that mbMSC and bmMSC presented a promising angiogenic potential. However, mbMSC seems to have additional advantages since it can be obtained by non-invasive procedure and expresses PDGF-B, an important molecule for vascular formation and remodeling.
\end{abstract}

Keywords: menstrual blood-derived mesenchymal stromal cells; bone marrow mesenchymal stromal cells; human umbilical vein endothelial cells; angiogenesis

\section{Introduction}

Over the past few decades, ischemic diseases are the most common causes of deaths in the world. Of this group, ischemic heart disease and stroke are the ones that require great attention [1], currently responsible for approximately 15 million deaths in 2019 [2], but also critical limb ischemia, 
a serious form of peripheral artery disease, represents the third most prevalent form of atherosclerotic cardiovascular disease [3]. The increasing burden of diseases related to the circulatory system has faced modern medicine to provide therapies that not only mitigate the symptoms of these diseases, but also facilitate the regeneration and function of the affected organs.

The idea of promoting increased blood perfusion in ischemic tissues via angiogenesis may be promising. Considering that ischemic disorders can be primarily caused by endothelial dysfunction, the logic behind therapeutic angiogenesis would be related to the promotion of vascular repair via endothelial cells and/or administration of growth factors [4-7]. However, the low efficiency of mature endothelial cells expansion as well as the reduced availability of endothelial progenitor cells (EPC) in postnatal tissues, generate limitations for the applicability of these cells in angiogenic therapy, in most cases [6,8]. On the other hand, mesenchymal stem/stromal cells (MSC) are multipotent cells that do not encounter such problems, can be isolated from several adult tissues, have low immunogenicity, and can be easily expanded in vitro in relatively short intervals [9-19]. In addition, several studies pointed out the beneficial effects of MSC in different disease models, mainly due to the paracrine secretion of pro-angiogenic, anti-apoptotic and anti-inflammatory trophic factors that can contribute to tissue repair [20-25]. The regenerative potential of MSC is so promising that several groups are already developing delivery methods of MSC on a 3D cell-delivery platform, which can be an alternative to improve cryoprotection, graft survival, angiogenic activity and prolonged cell function in vivo in order to explore the full potential of MSC in regenerative medicine [26].

Among the MSC sources extensively explored and used in the clinic [12,27-31], bone marrow mesenchymal stromal cells (bmMSC) are worth mentioning. However, it is hard to find donors, since human bone marrow is obtained by invasive and painful surgical procedure that use needles to withdraw liquid marrow from both sides of the pelvic bone. In this scenario, the search for other MSC sources was triggered. The discovery of menstrual blood as an MSC source offered a simple, safe, and painless alternative to bypass the invasiveness procedure [32,33]. The MSC obtained from different sources have different safety and efficacy profiles whose complete characterization is a sine qua non condition for their future use in clinical therapies [34]. Similar to MSC from other sources, menstrual blood-derived mesenchymal stromal cells (mbMSC) have great clonogenic capacity and multipotentialities in vitro [33,35-41]. The release of trophic factors as well as the modulation of the immune response are also beneficial aspects and make the clinical application of mbMSC even more interesting [18,42-45].

Considering that uterine endometrium undergoes intense ischemia followed by angiogenesis during the menstrual cycle, it is plausible that the MSC present in the endometrial environment and menstrual fluid could present advantageous angiogenic properties in relation to bone marrow MSC. In addition, once their angiogenic potential is confirmed, MSC derived from menstrual blood could be a more viable and renewable source for clinical application in ischemic disease therapies. Since there are few studies in the literature that compare the angiogenic potential of both MSC, this work sought to analyze and compare the angiogenic paracrine effects and intrinsic angiogenic capacity of these cells in vitro, besides to evaluate in vivo the possible contribution to angiogenesis of both MSC during chick embryo development.

\section{Results}

\subsection{Intrinsic Angiogenic Potential of MSC}

Sprouting assay evaluated the response of mesenchymal stem/stromal cells in relation to the initial stages of angiogenesis. After $48 \mathrm{~h}$ of cultivation in Matrigel ${ }^{\mathrm{TM}} \mathrm{GFR}$, many invasive cells appeared at the edge of the spheroid formed by the MSC of menstrual blood, with an average distance of $50.77 \pm 8.80 \mu \mathrm{m}$ (Figure 1A,C). On the other hand, the same was not observed in spheroids formed by bone marrow-derived MSC, which in turn, showed few cells beginning to invade the surrounding matrix and achieved shorter distances $(38.76 \pm 8.19 \mu \mathrm{m})$ (Figure 1B,C). When the culture period was extended to 
7 days, spheroids exhibited both single-cell invasion and coordinated, multicellular cord-like structure formation with numerous branches in all directions around the spheroid (Figure 1D,E). However, sprouting development of mbMSC was much more branched and reached longer distances when compared to bmMSC ( $358.51 \pm 62.44 \mu \mathrm{m}$ for mbMSC verses $99.99 \pm 31.89 \mu \mathrm{m}$, for bmMSC; Figure 1F).

Additionally, both MSC, in the most apical portion of the invasive cells, acquired morphological characteristics similar to endothelial cells during angiogenic sprouting, as shown by representative images of mbMSC spheroid in Figure 1G-G". Invasive cells were highly branched, with the presence of filopodia-like extensions in their extremities, being morphologically similar to tip cells (white arrow; Figure $\left.1 G^{\prime \prime}\right)$, which are activated endothelial cells that initiate angiogenic sprouting. In addition, MSC of the growing sprout, located just behind the cells of the extremity, were organized in a linear way and also reminds stalk cells (blue arrow, Figure $1 G^{\prime \prime}$ ).

Our next step was to investigate whether menstrual blood and bone marrow-derived MSC could also be differentiated into an endothelial-like phenotype, since morphological characteristics similar to tip cells and stalk cells were observed during the development of angiogenic sprouting. Immunofluorescence performed 14 days after plating sprouting experiment and in the presence of angiogenic endothelial medium revealed that $83.3 \%$ of the mbMSC $(n=5 / 6)$ and $60 \%$ of the bmMSC's spheroids $(n=3 / 5)$ evaluated expressed the CD31 molecule (Representative Figure $1 \mathrm{H}, \mathrm{K}$ ), suggesting that these cells could also be differentiating into an endothelial-like phenotype. Moreover, the filamentous actin of cytoskeleton was also stained with anti-phalloidin antibody (Figure 1I,L). Merged images of mbMSC and bmMSC are shown in Figure 1J,M, respectively.

\subsection{In Vitro Migration Capacity of MSC}

Scratch wound assay was performed with both MSC to assess their chemotactic motility in response to an injury stimulus. Percentages of relative wound density were quantified in each time point, over $48 \mathrm{~h}$, in order to evaluate scratch closure. Representative images used for this quantification of mbMSC and bmMSC are shown in Figure 2A,B, respectively. In addition, representative videos of mbMSC (Video S1) and bmMSC (Video S2) migration are available on Supplementary Materials. It is worth mentioning that at the end of $48 \mathrm{~h}$, the wound region is practically all occupied by both cell types. Migration curves were constructed for each cell type and revealed a greater slope of the bmMSC curve in relation to mbMSC, mainly in the initial $20 \mathrm{~h}$ of the experiment (Figure 2C).

In addition, bmMSC occupied a larger area of the wound region at the experimental times of $12 \mathrm{~h}$ $(p<0.01)$ and $24 \mathrm{~h}(p<0.05)$ compared to mbMSC. However, at the last time point, in $48 \mathrm{~h}$, densities in the wound region for both cell types become similar $(86.24 \pm 6.69 \%$ for mbMSC and $85.99 \pm 8.83 \%$ for bmMSC; Figure 2D), indicating that the mesenchymal cells from menstrual blood and bone marrow were able to reach the injury site and possibly exert its regenerative effect. Moreover, the area under the curve was also calculated in order to estimate migration velocity and showed that bmMSC occupied the wound region significantly faster over the experimental period, probably by the greater slope at the beginning (Figure 2E).

\subsection{In Vivo Migration Capacity and Survival: A Xenograft Assay Using Chick Embryos}

The xenograft assay was carried out with the purpose of identifying the location of the studied cells in a highly instructive and dynamic embryonic microenvironment, investigating whether MSC could migrate to specific regions in response to embryonic signals, as well as assessing whether these cells could participate in processes related to vasculogenesis and angiogenesis in vivo. Spheroids, instead of cell suspension, were used to ensure better accuracy and handling at the time of engraftment, as well as to allow assessing whether the cells would migrate from the implanted site to other regions of the embryo.

Fifty percent of the embryos used for grafting the spheroids were alive ( $n=4$ for each cell type) three days after surgery (E4.5-5, HH27). The engraftment caused a slight scar verified by a mild depression in the region of the cervical somites of the spinal column, as indicated by white arrows in 
Figure 3A,B. Nevertheless, this depression did not impair embryonic development and morphogenesis after visual and microscopic analyses.
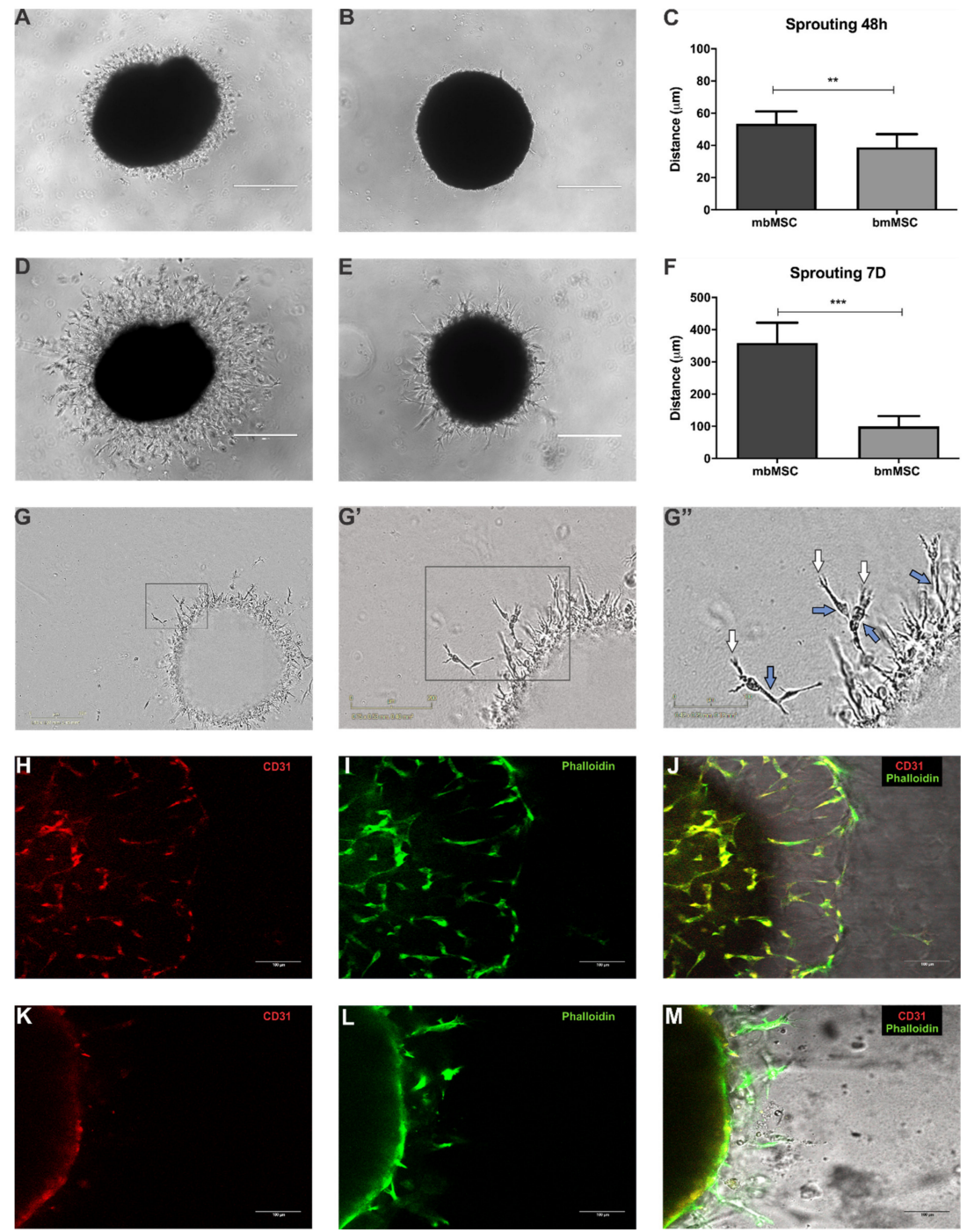

Figure 1. Sprouting from the 3D spheroids formed by mbMSC $(n=7)$ and bmMSC $(n=6)$. Representative images of (A) mbMSC and (B) bmMSC spheroids after $48 \mathrm{~h}$ in Matrigel $^{\mathrm{TM}}$ GFR with EGM-2 medium. mbMSC spheroids showed more invasive cells compared to bone marrow spheroids. (C) Quantitative analyses of sprout length after $48 \mathrm{~h}$. Distance reached by mbMSC spheroids was significantly longer than bmMSC spheroids $(50.77 \pm 8.80 \mu \mathrm{m}$ vs. $38.76 \pm 8.19 \mu \mathrm{m}$, ** $p<0.01$ ). Representative images of (D) mbMSC and (E) bmMSC spheroids after 7 days in Matrigel ${ }^{\mathrm{TM}}$ GFR with EGM-2 medium. mbMSC spheroids showed extensive development while sprouting of bmMSC spheroids was significantly reduced. (F) Quantitative analysis of sprout length after 7 days. Distance quantification of mbMSC-derived spheroids was significantly longer than of bmMSC (358.51 $\pm 62.44 \mu \mathrm{m}$ vs. $\left.99.99 \pm 31.89 \mu \mathrm{m}^{* * *} p<0.0001\right)$. (G-G") Representative images of mbMSC invasive cells in different magnifications showing morphological characteristics similar to endothelial cells. $\left(G^{\prime \prime}\right)$ Presence of filopodia-like extensions in their extremities, recapitulating morphologically to tip cells as indicated by white arrow and linear organization similar to stalk cells as indicated by blue arrow. (H-M) Immunofluorescence of $\operatorname{mbMSC}(n=6)$ and bmMSC $(n=5)$ spheroid after 14 days in culture. (H-K) mbMSC and bmMSC expressed CD31 during angiogenic sprouting assay as shown in red. $(\mathbf{I}, \mathbf{L})$ Cell's cytoskeleton is shown in green as indicated by phalloidin staining. $(\mathbf{J}, \mathbf{M})$ Merged images of immunofluorescence and phase contrast. All scale bars are indicated in the images. 
A
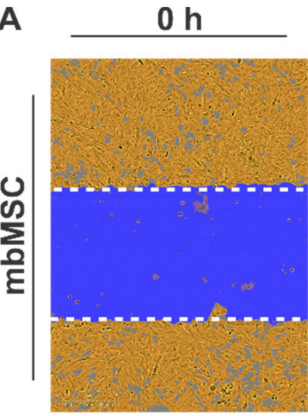

B
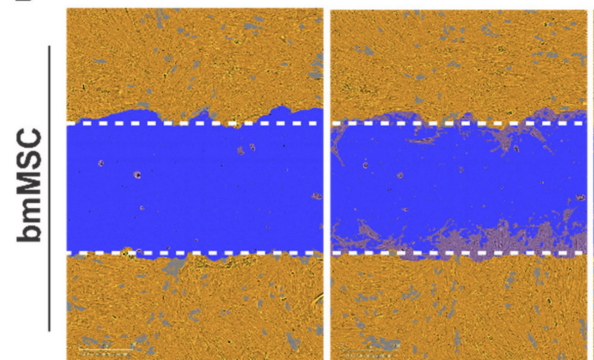

C

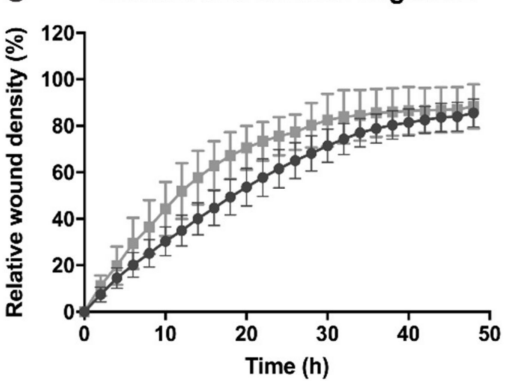

$12 \mathrm{~h}$
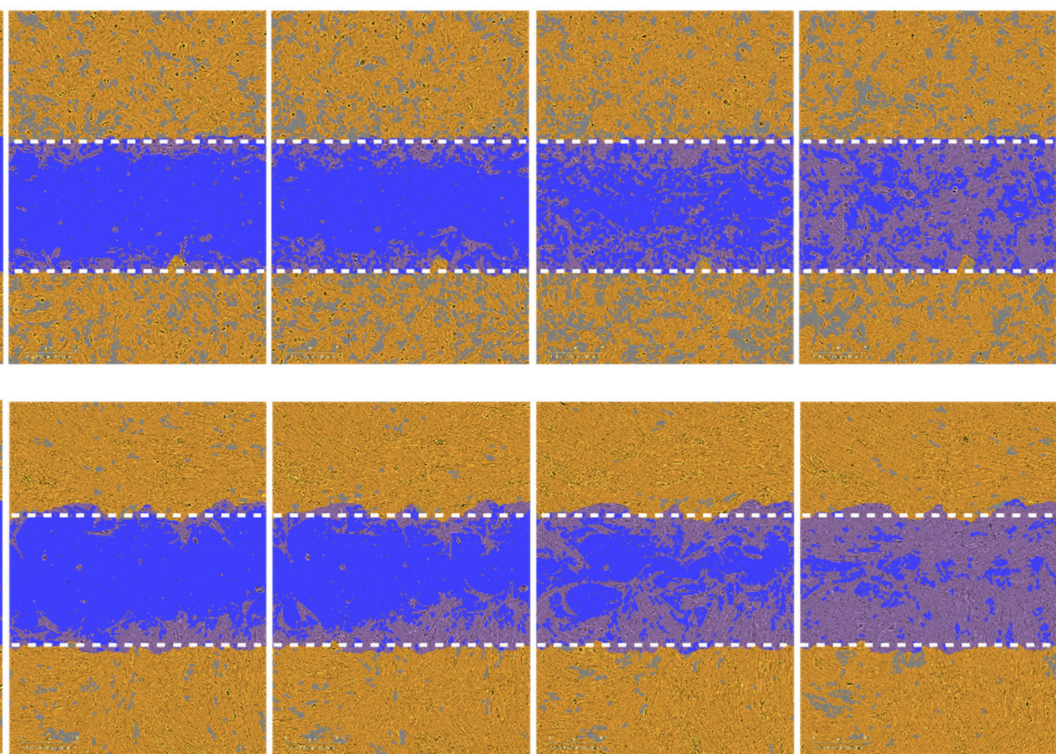

D

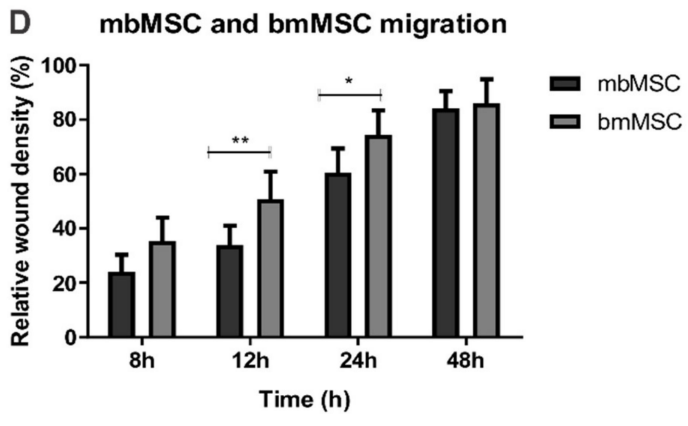

E AUC - MSC migration

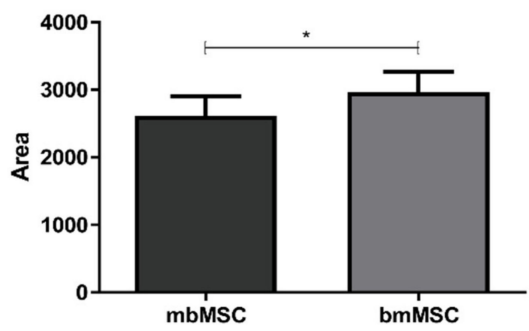

Figure 2. MSC migration capacity in vitro during scratch wound assay. $(\mathbf{A}, \mathbf{B})$ Representative images of (A) mbMSC and (B) bmMSC migration at the experimental times of 0, 8, 12, 24 and $48 \mathrm{~h}$ after scratch was performed. Cells around the wound are represented in orange, wound is represented in blue and migrated cells are represented in gray inside the blue region. Scale bars are $300 \mu \mathrm{m}$. (C) Migration curves of mbMSC $(n=7)$ and bmMSC $(n=7)$ over the 48-h experimental protocol. (D) Relative cell densities quantification at different time points after scratch was performed (mbMSC versus bmMSC after $12 \mathrm{~h},{ }^{* *} p<0.01$ and mbMSC versus bmMSC after $24 \mathrm{~h},{ }^{*} p<0.05$ ). (E) Area under the curve quantification indicated that bmMSC migrated faster than mbMSC $(* p<0.05)$. 

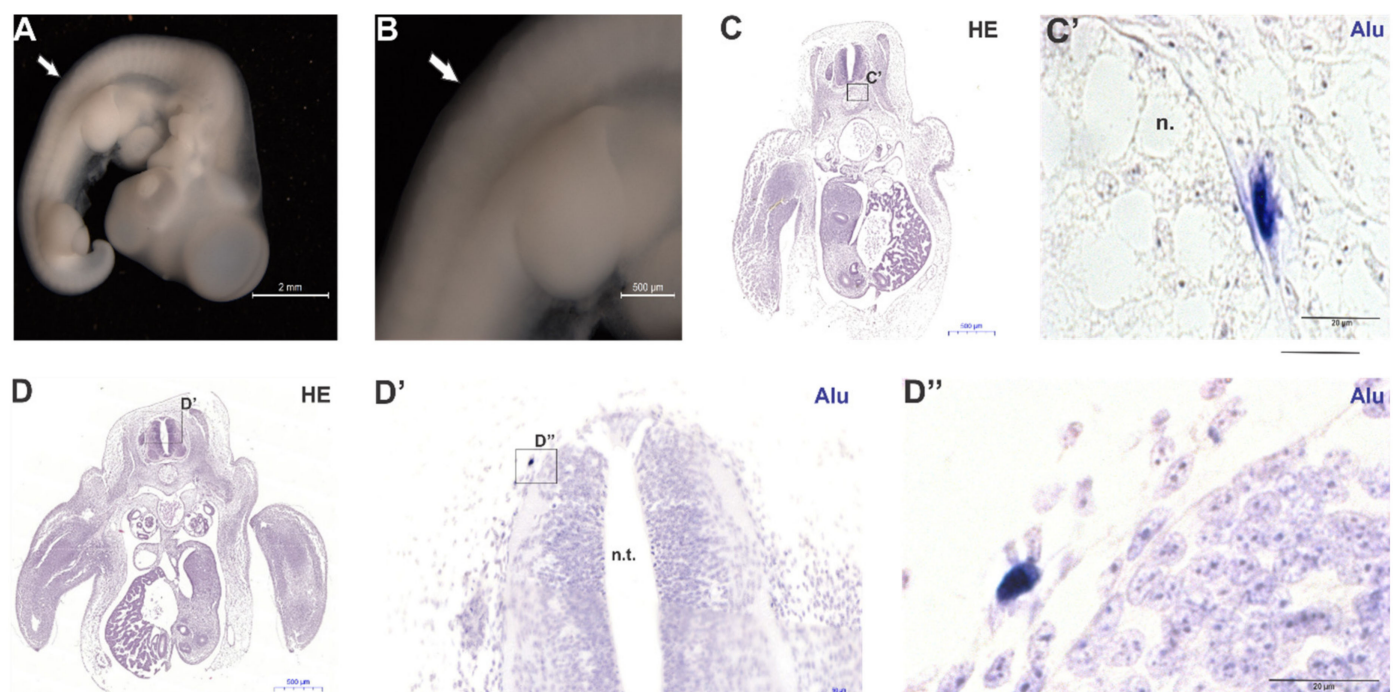

D'

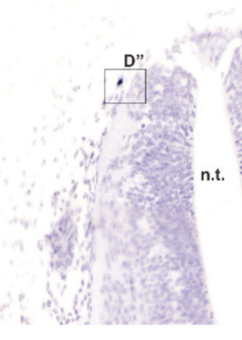

Alu

D"
E

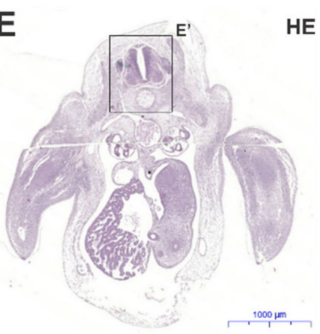

F

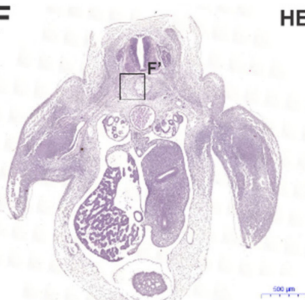

G

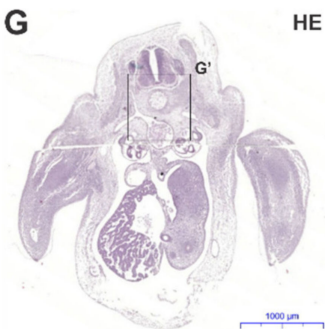

HE

HE
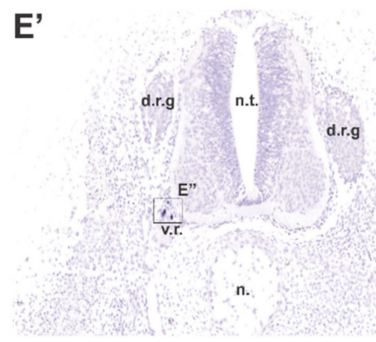

Alu
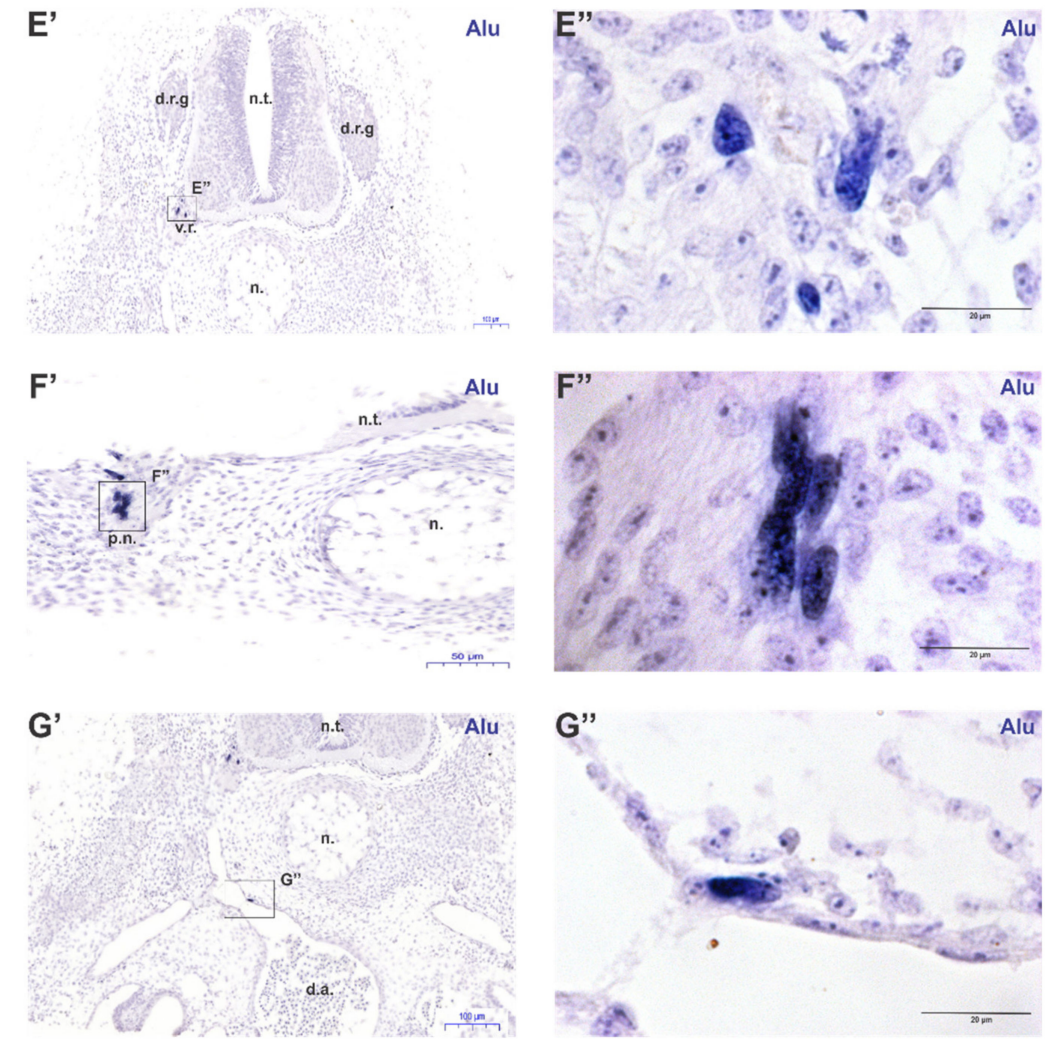

Figure 3. In vivo migration capacity of mbMSC during embryo development. (A,B) Representative photomicrographs of a E4.5-5 chick embryo after spheroid implantation. White arrows indicate a scar in the somatic region, where the engraftment was performed. (C-G) Hematoxylin and eosin staining of cross sections at the wing level. $\left(\mathbf{C}^{\prime}-\mathbf{G}^{\prime}, \mathbf{C}^{\prime \prime}-\mathrm{G}^{\prime \prime}\right)$ Sections adjacent to $(\mathbf{C}-\mathbf{G})$ counterstained with hematoxylin and hybridized with Alu probes. $\left(\mathbf{C}^{\prime}\right)$ Presence of $A l u$-positive mbMSC lateral to the notochord, in presumptive chondrogenic regions. ( $\mathbf{D}^{\prime}-\mathbf{D}^{\prime \prime}$ and $\left.\mathbf{E}^{\prime}-\mathbf{E}^{\prime \prime}\right)$ Alu-positive mbMSC were close to the basal lamina of the neural tube and ventral root, respectively. $\left(\mathbf{F}^{\prime}, \mathbf{F}^{\prime \prime}\right)$ Alu-positive mbMSC

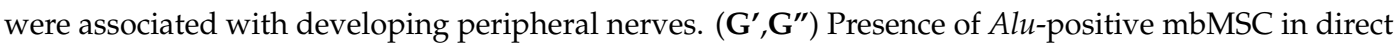
contact with the dorsal aorta endothelium of the chick embryo. All scale bars are indicated in the images. N.t., neural tube. d.a., dorsal aorta. n., notochord. d.r.g., dorsal root ganglion. v.r., ventral root. p.n.: peripheral nerve. 
Cross-sections hybridized with Alu probes showed that mbMSC migrated along with embryonic cell populations and integrated into host tissues. It is important to note that no cellular aggregate was found in the mesenchyme laterally to the neural tube, suggesting that these cells have mostly migrated to different regions of the chick embryo. Alu-positive mbMSC were located close to the notochord, representing $8.3 \%$ of total cells found $\left(n=2\right.$; Figure $\left.3 C, C^{\prime}\right)$. It is worth mentioning that cells derived from the sclerotome of somites migrate to these regions to form the future vertebrae of the axial skeleton of the embryo. Although endochondral ossification has not started at this stage of development, the notochord and surrounding area can be considered presumptive chondrogenic regions. So, mbMSC showed tropism for regions that form cartilage, corroborating to the chondrogenic potential already described for mbMSC in the literature [36,46]. Around $54.1 \%$ of the Alu-positive mbMSC were also found nearby the neural tube as well as at the ventral root, as shown in Figure 3D-D" and Figure 3E-E" $(n=13)$. We also observed that $33.3 \%$ of the mbMSC hybridized with an Alu probe $(n=8)$ were found in perineural niches, in association with the peripheral nerves of the embryo (Figure 3F-F"). In Figure 3F", it is possible to observe the intimate interaction of Alu-positive cells with the nerve fibers present in the mesenchyme inferior to the neural tube. Additionally, Alu-positive mbMSC $(4.1 \%)$ were found in a perivascular region, more specifically, in the endothelium of dorsal aorta of embryo at E4.5-5 (HH27) ( $n=1$, Figure 3G-G"), suggesting a possible participation in the processes involving embryonic vasculogenesis.

Moreover, our results showed that mbMSC were able to survive in the chick embryonic microenvironment, as well as being able to integrate into host tissues participating in morphogenesis (including vasculogenesis) together with embryo cells. However, we observed that few cells were found in the embryos in relation to the total number of transplanted cells, since spheroids had hundreds of cells and it was only found a maximum of 15 cells in an embryo.

In contrast to the mbMSC results, bone marrow-derived mesenchymal cells were not found in any of the four engrafted embryos. In this experiment we were able to evaluate, in an unprecedented way, the tropism of mbMSC for perivascular regions contributing to the formation of vessels and in regions proximal to meninges that are extremely instructive for vascular formation in this embryonic phase. These results show the high influence of bmMSC in angiogenesis, suggesting that this capacity could be explored in ischemic clinical therapies.

\subsection{Endothelial Tube-Like Formation Stimulated by MSC Conditioned Medium}

The human umbilical vein endothelial cell (HUVEC) lineage EA.hy926 (ATCC ${ }^{\circledR}$ CRL-2922 ${ }^{\mathrm{TM}}$ ), used for endothelial tube formation and migration assay, were evaluated in regard to CD31 expression and functional properties, as shown in Figure S1.

Representative images of tubular structures formed by HUVEC incubated with mbMSC and bmMSC conditioned medium, for 48 and $72 \mathrm{~h}$ of culture, carried out in normoxia and $1 \%$ hypoxia, are shown in Figure 4A-H.

Initially, the impact of 48 and 72-h conditioned media of mbMSC and bmMSC under normoxic and hypoxic conditions were compared to the angiogenic medium EGM-2. In regard to 48-h conditioned medium, the mbMSC were able to form tubular structures with total length (Figure 4I) and number of branches (Figure $4 \mathrm{~K}$ ) similar to EGM-2 in both $\mathrm{O}_{2}$ concentrations. However, only hypoxic bmMSC-CM promoted a similar number of branches compared to EGM-2 (Figure 4K). In regard to 72-h conditioned medium, again all cultured conditions of mbMSC promoted a total length (Figure 4J) and number of branches (Figure 4L) comparable to EGM-2. bmMSC-CM was similar to EGM-2 in relation to the number of branches, in both of $\mathrm{O}_{2}$ concentrations (Figure $4 \mathrm{~L}$ ). However, it did not achieve the same efficiency in the total length of the tubes (Figure $4 \mathrm{~J}$ ).

These data suggest that these mediums, mostly, exert an angiogenic effect comparable to EGM-2, which is the commercial medium rich in pro-angiogenic factors. Moreover, CM of longer culture periods, such as $72 \mathrm{~h}$, exhibited higher capacity to form tubular structures for both cells type, showing a longer total length and branch numbers (Figure 4J,L). 

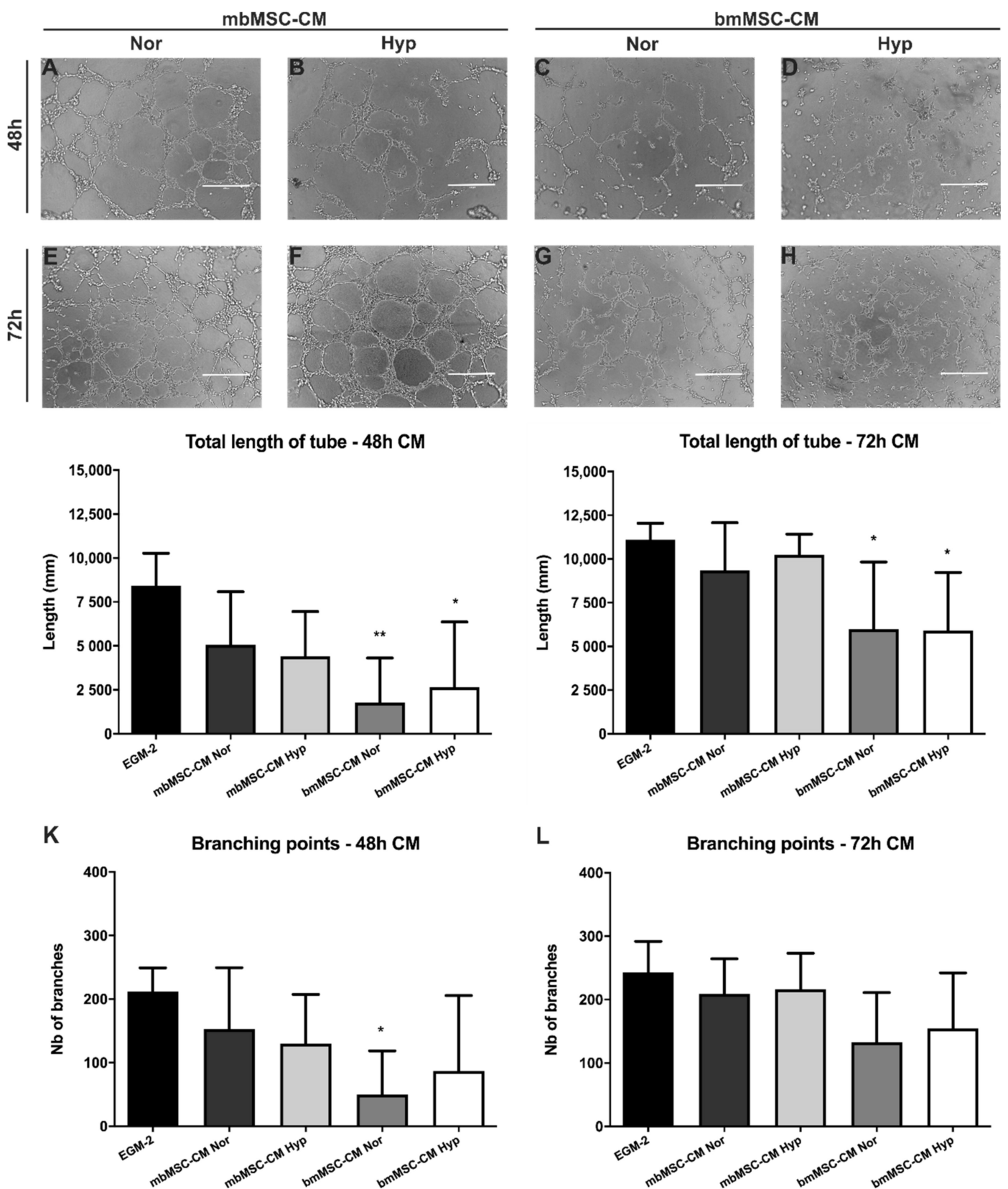

Figure 4. Endothelial tube-like formation stimulated by MSC conditioned medium. Representative phase contrast microscopy images of tubular structures formed by HUVEC EA.Hy926 incubated with (A,B,E,F) mbMSC and $(\mathbf{C}, \mathbf{D}, \mathbf{G}, \mathbf{H})$ bmMSC conditioned medium derived of (A-D) 48 and $(\mathbf{E}-\mathbf{H}) 72 \mathrm{~h}$ of culture, carried out in $(\mathbf{A}, \mathbf{C}, \mathbf{E}, \mathbf{G})$ normoxia and $(\mathbf{B}, \mathbf{D}, \mathbf{F}, \mathbf{H}) 1 \%$ hypoxia, $20 \mathrm{~h}$ after plating in Matrigel ${ }^{\mathrm{TM}}$ GFR with serum-free MSC conditioned media. (I,J) Quantification of the total length and $(\mathbf{K}, \mathbf{L})$ branches number of the tubular network formed by HUVEC cultivated with the 48 and $72 \mathrm{~h}-\mathrm{CM}$ of mbMSC and bmMSC. Values are expressed as mean \pm SD (EGM2 $48 \mathrm{~h}, n=4$; EGM-2 $72 \mathrm{~h}, n=5$; mbMSC and bmMSC-CM, $n=5$ for each condition); ${ }^{*} p<0.05 ;{ }^{* *} p<0.01$ compared to EGM-2. CM, conditioned medium. Nor, normoxia. Hyp, hypoxia. GFR, growth factor reduced. EGM-2, endothelial growth medium 2.

Another question to be addressed was whether there was a significant difference between these two cell types conditioned medium when compared to each other. Moreover, the influence of $\mathrm{O}_{2}$ concentration on the tubular structure's formation. In this context, no significant difference was detected between CM derived from both cell types, in different oxygen concentrations, suggesting that the MSC 
from both sources positively and quite similarly influence the angiogenic capacity of the endothelial cells. Although, we observed a general tendency for mbMSC to be slightly better than bmMSC.

\subsection{Impact of MSC Conditioned Medium on HUVEC Migration}

HUVEC migration in response to the conditioned media of MSC was evaluated through the scratch wound assay using the relative cell density quantification. Results showed that HUVEC migration curves shift downward when serum-free conditioned medium of mbMSC and bmMSC (Figure 5A,B) were used, independent of culture time, indicating that these medium impacts negatively on migration capacity and possible secreted factors by these cells did not overcome the absence of serum.

A

HUVEC migration - $48 \mathrm{~h}$ CM

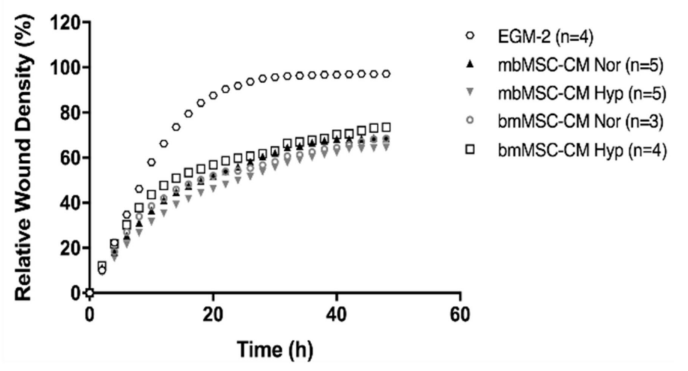

C

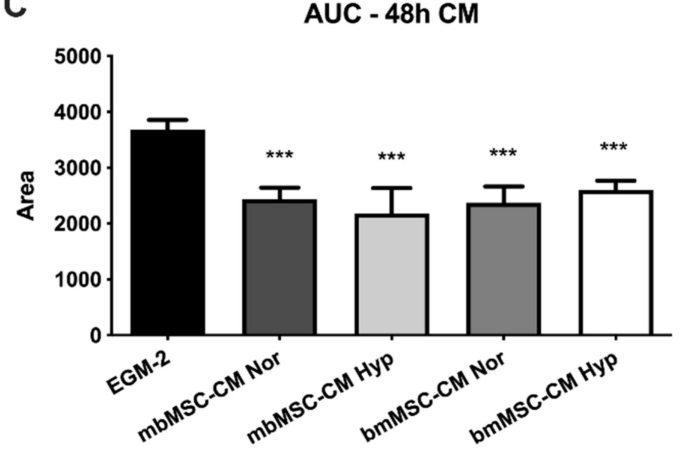

E



B

HUVEC migration - 72h CM

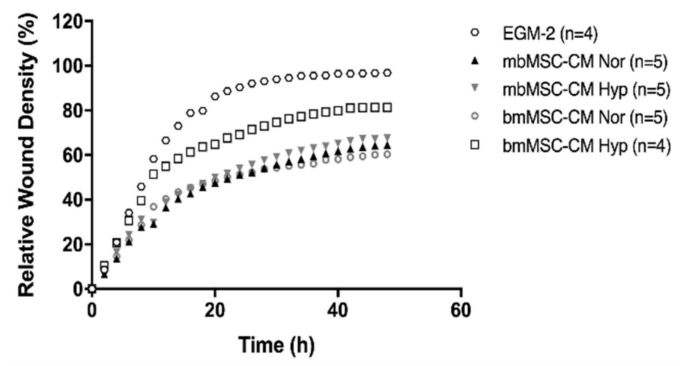

D

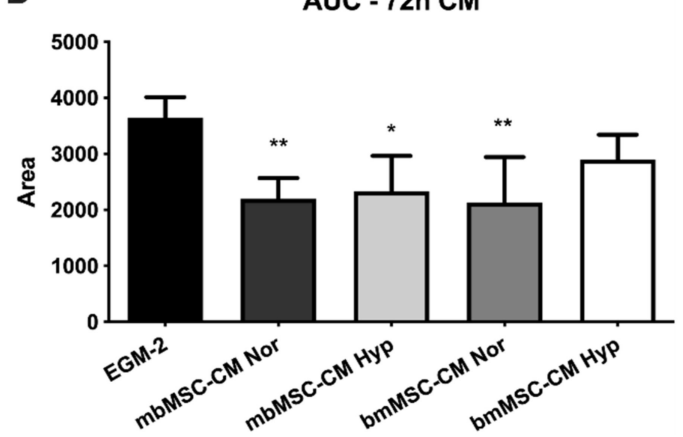

$\mathbf{F}$

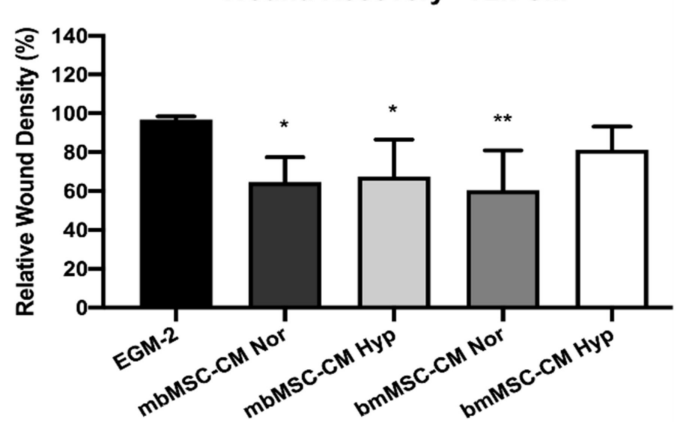

Figure 5. Impact of MSC conditioned medium over HUVEC EA.Hy926 migration by scratch wound assay in vitro. HUVEC migration curves in the presence of serum-free mbMSC and bmMSC-CM, obtained after (A) 48 and (B) 72-h of culture in normoxia and 1\% hypoxia. Sample size for each condition are indicated. (C,D) Area under the curve (AUC) relative to HUVEC migration curves in the presence of 48 and $72 \mathrm{~h}-\mathrm{CM}$ of mbMSC and bmMSC. (E,F) Wound recovery promoted by 48 and $72 \mathrm{~h}-\mathrm{CM}$ of mbMSC and bmMSC at the point of $48 \mathrm{~h}$ after scratch. Values are expressed as mean $\pm \mathrm{SD}$; ${ }^{*} p<0.05 ;{ }^{* *} p<0.01$; ${ }^{* * *} p<0.001$ compared to EGM-2. CM, conditioned medium. Nor, normoxia. Hyp, hypoxia. EGM-2, endothelial growth medium 2. 
Area under the curve (AUC) and wound recovery percentage at the time point of $48 \mathrm{~h}$ were also analyzed in order to compare the migratory profile in all conditions. Results showed that mbMSC and bmMSC serum-free conditioned media, obtained after 48 and $72 \mathrm{~h}$ of culture, promoted a significant smaller migration of HUVEC when compared to EGM-2, represented by the lowest area under the curve and lowest wound recovery quantification (Figure 5C-F), except for the bmMSC-CM obtained after $72 \mathrm{~h}$ of culture in hypoxia (Figure 5D,F). Despite both parameters having differed for only one condition of one cell type, results showed that at the end of the experimental protocol the absence of serum led to less coverage of the scratched area, indicating that fewer cells arrived in the target region compared to EGM-2.

Moreover, we investigate whether conditioned media obtained from normoxic and hypoxic conditions would interfere differently with the migratory capacity of HUVEC and also compare both types of cells with each other. Results showed that there was no difference in HUVEC migration when effects promoted by $\mathrm{CM}$ from both cells were compared to each other, showing that $\mathrm{CM}$ derived from mbMSC and bmMSC stimulated a similar migratory potential (Figure 5C-F). Although hypoxic bmMSC-CM $72 \mathrm{~h}$ was similar to EGM-2 condition, when compared the CM effect of both cells with each other (two-way ANOVA test), we found that hypoxia did not impair or improve the effect of both cells (Figure 5C-F) compared to normoxia.

\subsection{Angiogenic Related-Factors Expression in MSC}

In order to investigate the mechanism underlying this angiogenic effect promoted by the conditioned media of mesenchymal stromal cells in HUVEC, gene expression of three growth factors important for angiogenesis (PDGF-B, VEGF-A, and FGF2) were evaluated. PDGF-B was expressed only in mbMSC, similarly in all sample conditions, regardless of $\mathrm{O}_{2}$ concentration or experimental time (data not shown). Additionally, mbMSC and bmMSC expressed VEGF-A (Figure 6A,B) and FGF2 (Figure 6C,D) after both culture experimental time (48 and $72 \mathrm{~h}$ ). Moreover, no statistical difference was observed between mbMSC and bmMSC in relation to VEGF-A and FGF2 mRNA levels, regardless of cultivation time (Figure 6A-D).

A

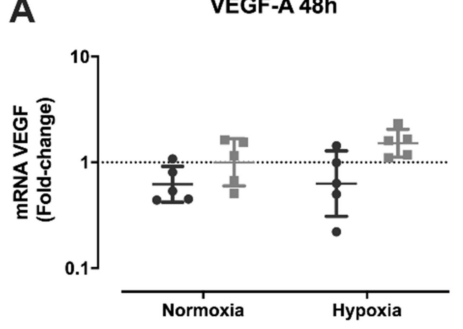

C

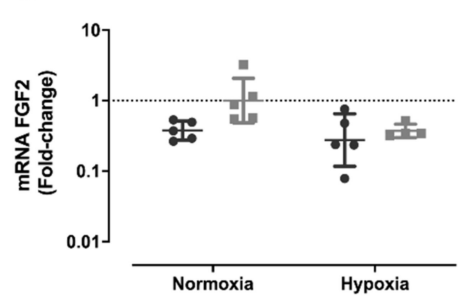

B VEGF-A $72 h$



D

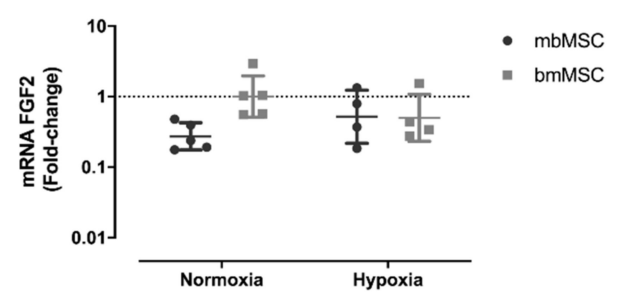

Figure 6. Expression of angiogenic growth factors VEGF-A and FGF2 after 48 and $72 \mathrm{~h}$ of culture in a serum-free condition by real time RT-PCR. (A-D) Comparison of mbMSC and bmMSC expression with each other, at different $\mathrm{O}_{2}$ concentrations. (A,B) VEGF-A expression in MSC cultured for 48 and $72 \mathrm{~h}$, respectively. (C,D) FGF2 expression in MSC cultured for 48 and $72 \mathrm{~h}$, respectively. For VEGF-A and FGF2 comparison, bmMSC in normoxia was used as a control group. Nor, normoxia; Hyp, hypoxia. RT-PCR, reverse transcription-polymerase chain reaction. VEGF-A, vascular endothelial growth factor A. FGF2, fibroblast growth factor 2 . 


\section{Discussion}

The present study analyzed the angiogenic properties of human mesenchymal stromal cells derived from bone marrow and menstrual blood in vitro, as well as assessed the MSC migration potential and interaction with the chick embryo tissues in vivo, identifying the location of these cells in a highly instructive and dynamic embryonic microenvironment in an unprecedented way.

In regard to MSC intrinsic angiogenic properties, sprouting assay in 3D culture model was performed as described by Montali et al. [47] in order to evaluate the response of mbMSC and bmMSC spheroids to the initial stages of angiogenesis. The angiogenic process is composed of multiple sequential steps, including tip cell selection, sprout formation, elongation, anastomosis, and vascular stabilization by support cells [7,48-51]. In this assay, both spheroids exhibited sprouting behavior and primitive tubule network formation. However, mbMSC spheroids showed significantly greater capacity for invasion in the surrounding matrix and formation of multicellular cord-like structures, in relation to bmMSC, in both experimental times evaluated ( $48 \mathrm{~h}$ and 7 days). Montali et al., also showed that bmMSC had a reduced angiogenic capacity when compared to the bone marrow subpopulation called mesangiogenic progenitor cell, evaluated by the in vitro sprouting assay and the in vivo chick embryo chorioallantoic membrane model, where a smaller contribution to neovascular formation was also observed [47]. Moreover, MSC at the invasion sprout front exhibited morphological characteristics similar to endothelial-like tip cells, showing emission of extensions similar to filopodia, and stalk cells organized in a linear manner, contributing to the growth and sprout elongation [52-55].

MSC spheroids exhibited sprouting behavior and morphology that showed important similarities to in vivo angiogenesis, suggesting that these cells could also be differentiating into an endothelial phenotype. The balance of VEGF-Dll4-Notch signaling is studied as a regulator of the differentiation of tip and stalk fate [56-59]. EGM-2 medium used in this assay has VEGF in its composition which possibly contributes to this acquired morphology of MSC. Moreover, it has already been demonstrated that MSC angiogenic factors are enhanced with spheroid formation compared to dissociated cells, including the production of VEGF $[60,61]$. Then, in order to investigate whether these cells also shared phenotypic characteristics with endothelial cells, the presence of the CD31 molecule was evaluated. In order to avoid residual contamination of CD31+ cells due to the heterogeneity of MSC cultures in initial passages, we used cells from passage 5 in this experiment. Like other mesenchymal stromal cells, mbMSC and bmMSC ordinarily did not express CD31 [32,35,37,62-64]. However, in this work both MSC appear to be going through endothelial differentiation, since there were positive cells for CD31. Despite few studies in the literature, our data corroborate with other groups that also observed endothelial phenotype in mbMSC and bmMSC $[33,65,66]$, grown under special conditions, as well as are aligned with data described for MSC from other sources, differentiated with specific protocols [67-70].

In addition to sprouting, the chemotactic migration of cells is an important step in the angiogenic process. So, we sought to mimic an injury microenvironment in vitro through the scratch wound assay and thus evaluate the migration of MSC in response to such stimulus in a 2D system. Our results showed that bmMSC migrated faster than mbMSC in the experimental times of $12 \mathrm{~h}$ and $24 \mathrm{~h}$ after scratching, as well as had higher AUC. These results suggest that bmMSC can respond more quickly to the trophic factors released by cells in the injury site and, therefore, are promptly mobilized and guided to the region where, probably, has a greater gradient of these factors. However, at the end of the experiment $(48 \mathrm{~h}$ ), cell densities of both MSC are very similar, indicating that they reached the same peak of migration. Jervis et al. reported that bovine bmMSC displayed higher proliferation rates than adipose tissue-MSC but no differences were detected in migration capacity between these cells after $24 \mathrm{~h}[71]$.

Additionally, our results were different from those found by Alcayaga and collaborators, who showed a higher migratory ability in mbMSC compared to bmMSC, in the experimental times of 12 and $24 \mathrm{~h}$ using the same experiment [72]. These conflicting results might be explained by the 
SDF-1A/CXCR4 axis which is involved in cells migration to sites of tissue damage and ischemia through hypoxia-inducible factor-1 (HIF-1) [34].

To assess MSC migration potential in vivo and engraftment survival, as well as the interaction of these cells in the embryonic microenvironment, we grafted the MSC-spheroid into the pre-somitic paraxial mesoderm of the embryo, in the region that will give rise to cervical somites at the wing bud level (15th-20th somites) [73]. Cells will receive stimulus from the transplanted region and these instructive signals can influence their migration potential, plasticity and cell destiny, allowing them to adopt different fates in the host organism. Our results showed that only mbMSC were able to survive in the chick embryonic microenvironment, as well as being able to integrate into host tissues, participating in morphogenesis along with embryo cells. mbMSC presented a tropism for presumptive chondrogenic regions of the chick embryo, since $8.3 \%$ of these cells were found in territories close to the notochord. Part of the sclerotome cells condenses around the notochord and neural tube, performing endochondral ossification in later stages. Therefore, mesenchymal cells in these regions means that they may also respond to the growth factors involved in the skeletal lineage, such as sonic hedgehog (shh) and noggin, secreted by the notochord and neural tube floor at this embryonic stage [74]. These results corroborated with the potential of this MSC already described in the literature, that when exposed to specific inducing factors, mbMSC can differentiate into cells of chondrogenic and osteogenic lineages [18,33,36,41,46,75].

In addition to the chondrogenic niche, mbMSC have also been found in perineural regions around the neural tube and ventral root. These regions are where the meninges will be formed, which the main functions are to protect the central nervous system and promote blood supply to it. Nimmagadda et al. noted that the first step in developing spinal cord meninges is the expression of the VEGFR-2 receptor in cells derived from the sclerotome immediately adjacent to the lateral surface of the neural tube [76]. This is due to the signals that are released through the neural tube during this developmental phase, including VEGF-A and BMP4, which recruit sclerotome-derived angioblasts and induce the formation of first blood vessels of the perineural vascular plexus [74,77]. Interestingly, $54.1 \%$ of mbMSC were found in these regions, suggesting that these cells may be responding to signals secreted by the neural tube at this development stage, which may even be proangiogenic stimuli. In addition, $33.3 \%$ of mbMSC were associated with peripheral nerves of the nervous system. Similar results were found by Cordeiro and cols. [78], in which observed that about $90 \%$ of the mesenchymal cells derived from adipose tissue (ADSC), transplanted also in the trunk region of the E1.5 (HH8-9) embryo, were found in perineural niches. Mesenchymal cell mobilization and recruitment to perineural regions may also suggest that these cells could participate in such events in vivo in the adult organism, contributing to repair processes of nervous tissue. Differentiation of mesenchymal cells from endometrial origin into neural-like cells has also been tested in vitro by some groups, proving this potential $[33,79,80]$. However, in vivo differentiation potential of mbMSC in neural-like lineages or another one derived from this somite region (cartilage, bone, muscle, dermis and endothelium) have not been tested in this work, being a possibility for future studies involving these cells.

Lastly, $4.1 \%$ of Alu-positive mbMSC migrated to perivascular regions, associating with the dorsal aorta endothelium of the chick embryo $\mathrm{E} 4,5-5$ (HH27). This result suggests that mbMSC may participate in events related to embryonic vasculogenesis, contributing to maturation and vascular stabilization, behaving as pericytes, possibly derived from portion of the somatic sclerotome [81]. Perivascular niche of human mesenchymal cells in adult individuals has already been described by several researchers and is currently accepted in the scientific community [82-87]. In addition, some authors suggested a possible perivascular localization of mbMSC in the basal and functional layer of human endometrium in vivo, due to the expression of molecules related to pericytes such as CD146, PDGFR- $\beta$ and SUSD-2, besides mesenchymal markers expression [88-91]. This reinforces the idea that chick embryonic microenvironment can also be used to check the potential or niche of cells in vivo.

In the second part of the study, we evaluated the paracrine effects of mbMSC and bmMSC's conditioned mediums on HUVEC EA.hy926 angiogenic capacity. Angiogenic paracrine effects of MSC 
conditioned medium have already been studied by several groups using different cell sources [72,92-96]. In this work, we sought to evaluate tube-like formation which is the ability to respond to an angiogenic stimulus. Our results showed that the conditioned media of both MSC had a beneficial angiogenic effect on HUVEC, probably due to secretion of angiogenic cytokines in the medium. Although no statistical difference was demonstrated between the two cell sources, we observed a general tendency for mbMSC to be slightly better than bmMSC. Compared to EGM-2, mbMSC had an effect apparently closer to angiogenic medium in regard to tube length and number or branching, than bmMSC. Alcayaga and cols. [72] found that mbMSC promotes higher formation of tubular structures in relation to bmMSC, in both oxygen concentration conditions. However, the authors cultivated MSC with $2 \%$ FBS, a condition that was not tested in our study. Besides, Jervis and cols. reported higher tubular networks formation after exposure to concentrated conditioned medium from bovine adipose tissue MSC compared to bmMSC on normoxic condition [71].

Moreover, serum-free conditioned medium of mbMSC and bmMSC, independent of culture time, impact negatively on HUVEC migration capacity compared to EGM-2, represented by the lowest area under the curve and lowest wound recovery quantification, except for the bmMSC-CM obtained after $72 \mathrm{~h}$ of culture in hypoxia. In addition, there was no difference in HUVEC migration when CM of both cell lines was compared with each other.

Different conditions (hypoxia and starving) might lead to different protein expression profiles and consequently their effects [97]. Probably this is also one of the reasons we see such a huge difference in the HUVEC's migration curve with CM-MSC compared to EGM-2. The conditioned medium also has soluble products and metabolites excreted by the cells in culture [98], which in some cases could negatively influence its results. It is important to remember that the EGM-2 condition did not have contact with such products of cellular metabolism.

Since there was, mostly, a benefic angiogenic effect of the conditioned media of MSC on endothelial cells, growth factors expression was evaluated. Both MSC expressed VEGF and FGF2 in both $\mathrm{O}_{2}$ concentrations, with no statistical difference between them. Hypoxia frequently can upregulate the expression of some angiogenic cytokines, such as VEGF [99], although this was not observed in this work. Besides that, only mbMSC samples expressed PDGF-B. These data are partially similar to studies developed by Jiang and collaborators that demonstrated that MSC from endometrium expressed significantly higher levels of PDGF mRNA compared to MSC from bone marrow, in normoxia and $1 \%$ hypoxia after $24 \mathrm{~h}$ of incubation [100]. Similarly, Meng and cols. reported superior capacity of endometrial stem cells in secreting PDGF-BB when compared to umbilical cord-derived mesenchymal cells. In addition, metalloproteases (MMP-3 and MMP-10), GM-CSF and ANG-2 were constitutively present in the culture media of endometrial stem cells. Comparable secretion of angiogenic factors such as VEGF, HGF, and EGF was observed between both cells [33].

These results demonstrate that mbMSC may secrete a distinct set of cytokines and growth factors that could be important therapeutically. Although both MSC have a positive angiogenic effect on HUVEC in vitro, the fact that menstrual blood-derived MSC also express significant amounts of PDGF-B, can suggest a more complete angiogenic contribution, since this cytokine participate both in the formation and in the vascular remodeling of an ischemic tissue.

\section{Materials and Methods}

\subsection{Isolation and Maintenance of $m b M S C$ and $b m M S C$}

The use of human menstrual blood was approved by the Clementino Fraga Filho University Hospital's Ethics Committee (52627716.7.0000.5257, 1 February 2016) and the bone marrow was approved by the Bonsucesso Federal Hospital's Ethics Committee (26046414.7.0000.5253, 1 May 2014). All donors provided signed informed consent in accordance with the principles of the Declaration of Helsinki. 
mbMSC were isolated and maintained as previously described by our group $[37,62]$. Menstrual blood was collected from seven healthy volunteer woman in reproductive age $(n=7)$ using a proper collector cup containing $5 \mathrm{~mL}$ of $1 \times$ phosphate buffered saline (PBS-LGC BIOTECNOLOGIA, pH 7.2), $100 \mathrm{U} / \mathrm{mL}$ penicillin and $100 \mathrm{mg} / \mathrm{mL}$ streptomycin (Gibco). Samples were washed twice with PBS and were cultured in high glucose Dulbecco's modified Eagle's medium (DMEM; Sigma-Aldrich), supplemented with $20 \%$ fetal bovine serum (FBS-Gibco), $2 \mathrm{mM} \mathrm{L-glutamine} \mathrm{(Sigma-Aldrich),} 50 \mathrm{U} / \mathrm{mL}$ penicillin and $50 \mu \mathrm{g} / \mathrm{mL}$ streptomycin (Gibco). Medium was changed after two days to remove non adherent cells and cells were maintained at $37{ }^{\circ} \mathrm{C}$ in a $5 \% \mathrm{CO}_{2}$ incubator. For cellular expansion, adherent cells were detached using $0.25 \%$ trypsin EDTA (Gibco), counted and sub-cultured.

bmMSC were isolated and maintained as previously described by our group [101]. Briefly, bone marrow aspirates were collected from seven hip surgery patients ( $n=7 ; 18$ to 60 years old). The material was processed using Ficoll-Paque ${ }^{\mathrm{TM}}(1.077 \mathrm{~g} / \mathrm{mL}$, GE Healthcare) and mononuclear cells were isolated and cultured at the same conditions as mbMSC, except for the serum, which used 15\% FBS (Hyclone, Thermo Fisher Scientific, Waltham, MA, US).

All the experiments were performed using these cells at passages P3 to P9. The comparative experiments were performed with the cells in paired passages. Cells were routinely tested for mycoplasma (TaKaRa PCr Mycoplasma detection Kit, TaKaRa Bio Inc, Kusatsu, Shiga, JP; cat. 6601).

\subsection{D Angiogenic Sprouting Assay}

Tridimensional spheroids were generated by the hanging drop method. Drops $(20 \mu \mathrm{L})$ of mbMSC and bmMSC suspensions $\left(1.5 \times 10^{5}\right.$ cells/drop) were laid on the inner surface of a Petri dish lid. To prevent hanging drop dry, $7 \mathrm{~mL}$ of PBS were added to Petri dishes and incubated in normoxic condition overnight at $37^{\circ} \mathrm{C}$ in $5 \% \mathrm{CO}_{2}$ for cellular aggregation. Spheroids were gently applied to a Flat bottom 96-well plate (Greiner Bio One, cat. 655986) previously coated with Matrigel ${ }^{\mathrm{TM}}$ Growth Factor Reduced (GFR) basement membrane matrix (BD Biosciences, San Jose, CA, US) and cultured in EGM-2 medium (Lonza, cat. CC-3156). Sprouting was evaluated after $48 \mathrm{~h}$ and 7 days. Images were acquired by phase-contrast inverted microscope Evos AMG (Thermo Fisher Scientific) and evaluated by measuring the distances between the spheroid edge and the last invading cell of sprouts by Image-Pro Plus software. After image analysis, 3D spheroids were cultured for more than 7 days and then were processed for immunofluorescence.

\subsection{MSC-Spheroids' Immunofluorescence}

On the 14th day of culture, the sprouting spheroids were fixed in $4 \%$ formaldehyde for $30 \mathrm{~min}$ at room temperature. Spheroids were permeabilized for $30 \mathrm{~min}$ in $0.1 \%$ Triton X-100 (Sigma-Aldrich) and blocked in 2\% BSA (Sigma-Aldrich, Saint Louis, MO, US), both diluted in PBS, for $2 \mathrm{~h}$ at room temperature. All antibodies were diluted in 2\% BSA with PBS. For cell washing, $0.05 \%$ Tween-20 (Sigma-Aldrich) in PBS was used. CD31 primary antibody (R\&D Systems, cat. BBA7, clone 9G11) was diluted 1:50 and incubated with spheroids at $4{ }^{\circ} \mathrm{C}$ overnight. The next day, three more washes were performed and then spheroids were incubated with secondary antibody, goat anti-mouse IgG H\&L Cy3-conjugated (1:200; Abcam, Cambridge, CAM, UK; cat. ab97035), for one hour at room temperature. After three more washes, spheroids were subsequently stained with Phalloidin antibody conjugated with Alexa Fluor 488 (1:500; cat. A12379, Thermo Fisher) for cytoskeletal labeling. Finally, three washings were performed with PBS, $200 \mu \mathrm{L}$ of PBS were added per well and $20 \times$ magnification photomicrographs were acquired on the LSM 510 laser scanning microscope (Zeiss). The system was linked to the software Zen 2009 that processed the images obtained.

\subsection{In Vitro Cell Migration Assay}

HUVEC, mbMSC and bmMSC migration capacity was evaluated in a scratch assay, where $2 \times 10^{4}$ cells per well were grown separately in 96-well plate (Essen Bioscience Image Lock; Ann Arbor, MI, US) to full confluence. A straight scratch was accurately performed on the cell monolayer using the 
Wound Maker device (Essen Bioscience, Ann Arbor, MI, US) and cells were washed twice with PBS to remove debris. HUVEC were incubated with mbMSC and bmMSC conditioned medium or endothelial media (EGM-2). However, for mesenchymal stromal cells, after performing the scratch, instead of the conditioned medium, the respective culture medium of each cell type was used. Images at $10 \times$ magnification were acquired for each sample every $2 \mathrm{~h}$ for a period of $48 \mathrm{~h}$ using Incucyte ZOOM automated inverted microscope (Essen Bioscience) to monitor cell migration into the wound area. Migration capacity was quantified using the Relative Wound Density (RWD) algorithm of the software INCUCYTE ZOOM version 2015.A, which allows calculating the density of the wound region as a function of the density of the cell region and is defined by the following Equation (1):

$$
\% \operatorname{RWD}(\mathrm{t})=100 \times \frac{(\mathrm{w}(\mathrm{t})-\mathrm{w}(0))}{(\mathrm{c}(\mathrm{t})-\mathrm{w}(0))}
$$

where:

$\mathrm{w}(\mathrm{t})=$ Density of wound region at time, $(\mathrm{t})$

$c(t)=$ Density of cell region at time, $(t)$

\section{5. mbMSC and bmMSC Spheroids Generation for Chick Embryo Xenograft}

Spheroids formed from mbMSC and bmMSC in passage 7 were prepared as described by Brito et al. [102]. Briefly, cells were seeded in high density $\left(5 \times 10^{5}\right.$ cells $\left./ \mathrm{mL}\right)$ and plated in $60 \mathrm{~mm}$ Petri dishes, untreated for cell adhesion (J prolab), using the same culture medium previously described, for $48 \mathrm{~h}$.

\subsection{Chick Embryos Manipulation}

The protocols used for handling chick embryos were all approved by the Ethics Committee on the Use of Animals in Scientific Experimentation (Health Sciences Centre of the Federal University of Rio de Janeiro).

Eggs of white Leghorn chicken (Gallus gallus) were obtained from Granja Tolomei (Rio de Janeiro, RJ, BR) and staged according to HH stages [103] or the total number of somites (somite stage, ss). For grafting cells in the somitic region, chick embryos were incubated at $37^{\circ} \mathrm{C}$ until they reached at least the thirteenth somite stage (13ss; HH11), on the second embryonic day (E2). On this day, prior to engraftment, albumin excess was aspirated from the eggs by, carefully, opening a small hole in each shells. Then, a window was opened in the upper central part of the egg and India ink (Nankin) was injected into the yolk to allow better visualization of the embryo structures and counting the number of somites. One spheroid of mbMSC or bmMSC (approximately of the size of a chick somite) was grafted into the presomitic mesoderm (PSM) of the presumptive 15-20 somites, at the future wing bud level [73]. The spheroid was inserted into the PSM through a cut in the ectoderm. Grafted embryos ( $n=8$ for each cell type) were reincubated at $37^{\circ} \mathrm{C}$ to develop until E5 (HH27). On the fifth day of embryonic development, embryos were euthanized and the specimens prepared for histology.

\subsection{Genomic In Situ Hybridization with Alu Probes}

Embryos were fixed using a Formoy solution [Ethanol (Merck) - 37\% Formaldehyde (Vetec)-Acetic acid (Merck) in proportions 6: 3: 1, respectively)], dehydrated with ethanol (Merck, Darmstadt, HE, DE) and xylene (Vetec) and embedded in Paraplast (Sigma-Aldrich). Serial sections of $7 \mu \mathrm{m}$ were performed using a manual microtome (Leica Biosystems, Buffalo Grove, IL, USA) and mounted on silanized slides (Kasvi, São José dos Pinhais, PR, BR).

Human Alu probes used in this work were synthesized by PCR from adipose-derived mesenchymal stromal cells as described by Cordeiro et al. [78]. Genomic in situ hybridization of Alu probes on histological sections was performed as previously described [104]. Probes were localized using anti-digoxigenin-AP, Fab fragments (cat. 11093274910, Roche) were diluted 1:2000 in PBS, and were 
detected using NBT (Roche) and BCIP (Sigma-Aldrich) as substrates. To assemble, slides were washed three times in PBS, counterstained with hematoxylin (Sigma-Aldrich), dehydrated with ethanol/xylene (Merck/Vetec) and mounted with Entellan ${ }^{\circledR}$ new (Merck, Darmstadt, HE, DE). In sections adjacent to those labeled with Alu probes, hematoxylin-eosin (Sigma-Aldrich) staining was performed following a routine protocol [105].

The micrographs were taken using the Axioplan microscope with the Axiovision software (Carl Zeiss Microscopy, Oberkochen, BW, DE) and the Pannoramic MIDI II digital slide scanner (3DHISTECH, Budapest, PE, HU) with Caseviewer software (3DHISTECH).

\subsection{MSC Conditioned Medium Collection}

mbMSC and bmMSC were grown in a $60 \mathrm{~mm}$ plate at a concentration of $4 \times 10^{5}$ cells for 48 and $72 \mathrm{~h}$ with DMEM without serum, in normoxic $\left(21 \% \mathrm{O}_{2}\right)$ and hypoxic $\left(1 \% \mathrm{O}_{2}\right)$ conditions. After these times of incubation, the conditioned medium (CM) were collected and centrifuged at $400 \times g$ for five minutes to remove debris. The supernatants were used for endothelial tube formation and migration assays.

\subsection{Endothelial Tube Formation Assay}

Human umbilical vein endothelial cells at concentration of $2 \times 10^{4}$ cells per well were plated in 96-well plate (Corning ${ }^{\circledR}$, Corning, NY, USA), coated with Matrigel ${ }^{\mathrm{TM}}$ GFR basement membrane matrix (BD Biosciences), in the presence of mbMSC and bmMSC conditioned medium, cultured for 48 or $72 \mathrm{~h}$. Endothelial Growth Medium (EGM-2-Lonza, Basel, BS CH) was used as control. After $20 \mathrm{~h}$, images at $10 \times$ magnification were acquired by phase-contrast inverted microscope Evos AMG (Thermo Fisher Scientific). Angiogenic capacity of HUVEC was analyzed by quantifying the total length of tubes and the number of branches in each experimental condition using the ImageJ software with angiogenesis analyzer extension.

\subsection{Gene Expression Analysis of Angiogenic-Related Molecules}

Total RNA of mbMSC and bmMSC cultured in normoxic and hypoxic conditions were extracted using RNeasy Mini Plus kit (Qiagen, Germantown, MD, USA). The cDNA was synthesized from $0.5 \mu \mathrm{g}$ of total RNA by reverse transcription reaction using the High-capacity Reverse Transcription Kit (Applied Biosystems, Carlsbad, CA, USA) following the manufacturer's instructions. Real-time PCR amplifications were carried out using the 7500 Real-Time PCR System (Applied Biosystems). The amplification reactions were performed in duplicate in a final volume of $15 \mu \mathrm{L}$ each that contained $3 \mu \mathrm{L}$ of diluted cDNA (1.5 ng) in RNase-free water, $7.5 \mu \mathrm{L}$ of $2 \times$ power SYBR (Applied Biosystems), $4 \mu \mathrm{L}$ RNase-free water and $0.5 \mu \mathrm{L}$ of the primer sense and antisense in the concentration of $10 \mu \mathrm{M}$. The amplification conditions were heated up to $50^{\circ} \mathrm{C}$ for $2 \mathrm{~min}$, followed by denaturation and activation of Taq polymerase at $95^{\circ} \mathrm{C}$ for $10 \mathrm{~min}, 40$ cycles of denaturation at $95^{\circ} \mathrm{C}$ for $15 \mathrm{~s}$, annealing at $60^{\circ} \mathrm{C}$ for $30 \mathrm{~s}$ and extension at $72^{\circ} \mathrm{C}$ for $30 \mathrm{~s}$. Transcript levels of the target genes were normalized using GAPDH housekeeping gene as an internal control. Relative gene-specific transcript levels were calculated by the $2^{-(\Delta \Delta \mathrm{Ct})}$ method, where $\Delta \Delta \mathrm{Ct}=[(\Delta \mathrm{Ct}$ experimental $-\Delta \mathrm{Ct}$ control $)]$. The $\Delta \mathrm{CT}$ control represents the $\Delta \mathrm{CT}$ means of the bmMSC in normoxia. Results were presented on a logarithmic scale at base 10. Primers sequences are shown in Table S1 (Supplementary Materials).

\subsection{Statistical Analysis}

Data was analyzed using Graphpad Prism 8 Software. Student's $t$-test were used to analyze differences between two groups. One-way or two-way ANOVA followed by Bonferroni multiple comparison post-hoc test was used to analyze differences between three or more groups. Data are presented as mean $\pm \mathrm{SD}$, unless stated otherwise. $p$-value less than 0.05 was considered statistically significant. 


\section{Conclusions}

In this work, mbMSC demonstrated a greater capacity to invade into the surrounding matrix and to form multicellular cord-like structures in 3D-culture. However, both MSC share endothelial characteristics during angiogenic sprouting, seen by the similarity to tip cells, stalk cells and CD31 expression. Moreover, mbMSC and bmMSC were able to migrate after scratch wound in vitro, nonetheless, only mbMSC demonstrated the ability to migrate and integrate into host tissues in vivo, responding in a particular way to different embryonic signals, being able to engraft in perivascular, perineural and chondrogenic regions.

Conditioned medium of mbMSC and bmMSC were able to stimulate the formation of tubular structures and chemotactic migration in HUVEC regardless of oxygen availability, suggesting that both MSC can contribute efficiently to angiogenesis in several conditions of the microenvironment, including oxygen deprivation. In addition, VEGF-A and FGF2 mRNA were detected in both MSC, besides only mbMSC expressed PDGF-B, suggesting a more complete angiogenic contribution, being able to participate in both formation and vascular remodeling. Finally, we can suggest that mbMSC may prove to be a good alternative for therapeutic angiogenesis, mainly because it is a less invasive source and shows intrinsic and paracrine angiogenic properties in vitro.

Supplementary Materials: The following are available online at http://www.mdpi.com/1422-0067/21/24/9563/s1, Figure S1: Umbilical cord vein endothelial cell lineage EA.Hy926 maintained morphology, phenotype and functional properties in vitro. Table S1: Primers used in order to evaluate angiogenic-related molecules. Video S1: mbMSC migration on scratch wound assay. Video S2: bmMSC migration on scratch wound assay.

Author Contributions: Conceptualization, R.d.A.S., K.D.A., and R.C.d.S.G.; methodology, R.d.A.S., K.D.A., J.H.O.d.B., I.R.C., J.M.d.B.N., R.C.S.d.M., and T.H.K.-B.; formal analysis, R.d.A.S., J.H.O.d.B., K.D.A., T.H.K.-B., and R.C.d.S.G.; writing-original draft preparation, R.d.A.S. and K.D.A.; writing-review and editing, R.C.S.d.M., T.H.K.-B., J.H.O.d.B., I.R.C., and J.M.d.B.N., and R.C.d.S.G; supervision, R.C.d.S.G and J.M.d.B.N.; project administration, R.C.d.S.G.; funding acquisition, R.C.d.S.G. All authors have read and agreed to the published version of the manuscript.

Funding: This research was funded by the National Center of Science and Technology for Regenerative Medicine/REGENERA grant number 465656/2014-5, National Research Council/CNPq grant number 401816/2016-8, Rio de Janeiro Research State Foundation/FAPERJ grant number E-26/202.963/2017, Brazilian Council for Scientific and Technological Development (CNPq) grant number 465656;2014-5, and the Coordination for the Improvement of Higher Level Personnel (CAPES) for scholarship support.

Conflicts of Interest: The authors declare no conflict of interest.

\section{Abbreviations}

ANG-2 Angiopoietin 2

BMP-4 Bone morphogenetic protein 4

EGM-2 Endothelial growth medium

HGF Hepatocyte growth factor

MSC Mesenchymal stromal/stem cell

mbMSC Menstrual blood-derived mesenchymal stromal cells

bmMSC Bone marrow mesenchymal stromal cells

HUVEC Human umbilical vein endothelial cells

FGF2 Basic fibroblast growth factor

PDGF-B Platelet-derived growth factor subunit B

VEGF-A Vascular endothelial growth factor A

\section{References}

1. Virani, S.S.; Alonso, A.; Benjamin, E.J.; Bittencourt, M.S.; Callaway, C.W.; Carson, A.P.; Chamberlain, A.M.; Chang, A.R.; Cheng, S.; Delling, F.N.; et al. Heart Disease and Stroke Statistics-2020 Update: A Report from the American Heart Association. Circulation 2020, 141, e139-e596. [CrossRef] [PubMed]

2. WHO. The Top 10 Causes of Death. Available online: https://www.who.int/news-room/fact-sheets/detail/ the-top-10-causes-of-death (accessed on 13 December 2020). 
3. Fowkes, F.G.; Rudan, D.; Rudan, I.; Aboyans, V.; Denenberg, J.O.; McDermott, M.M.; Norman, P.E.; Sampson, U.K.; Williams, L.J.; Mensah, G.A.; et al. Comparison of global estimates of prevalence and risk factors for peripheral artery disease in 2000 and 2010: A systematic review and analysis. Lancet 2013, 382, 1329-1340. [CrossRef]

4. Silvestre, J.S.; Smadja, D.M.; Lévy, B.I. Postischemic revascularization: From cellular and molecular mechanisms to clinical applications. Physiol. Rev. 2013, 93, 1743-1802. [CrossRef] [PubMed]

5. Sanz-Nogués, C.; O’Brien, T. In vitro models for assessing therapeutic angiogenesis. Drug Discov. Today 2016, 21, 1495-1503. [CrossRef]

6. Tao, H.; Han, Z.; Han, Z.C.; Li, Z. Proangiogenic Features of Mesenchymal Stem Cells and Their Therapeutic Applications. Stem Cells Int. 2016, 2016, 1314709. [CrossRef]

7. Johnson, T.; Zhao, L.; Manuel, G.; Taylor, H.; Liu, D. Approaches to therapeutic angiogenesis for ischemic heart disease. J. Mol. Med. 2019, 97, 141-151. [CrossRef]

8. Zhao, L.; Johnson, T.; Liu, D. Therapeutic angiogenesis of adipose-derived stem cells for ischemic diseases. Stem Cell Res. Ther. 2017, 8, 125. [CrossRef]

9. Lee, M.; Jeong, S.Y.; Ha, J.; Kim, M.; Jin, H.J.; Kwon, S.J.; Chang, J.W.; Choi, S.J.; Oh, W.; Yang, Y.S.; et al. Low immunogenicity of allogeneic human umbilical cord blood-derived mesenchymal stem cells in vitro and in vivo. Biochem. Biophys. Res. Commun. 2014, 446, 983-989. [CrossRef]

10. Abomaray, F.M.; Al Jumah, M.A.; Alsaad, K.O.; Jawdat, D.; Al Khaldi, A.; AlAskar, A.S.; Al Harthy, S.; Al Subayyil, A.M.; Khatlani, T.; Alawad, A.O.; et al. Phenotypic and Functional Characterization of Mesenchymal Stem/Multipotent Stromal Cells from Decidua Basalis of Human Term Placenta. Stem Cells Int. 2016, 2016, 5184601. [CrossRef]

11. Girdlestone, J. Mesenchymal stromal cells with enhanced therapeutic properties. Immunotherapy 2016, 8, 1405-1416. [CrossRef]

12. Hendijani, F. Explant culture: An advantageous method for isolation of mesenchymal stem cells from human tissues. Cell Prolif. 2017, 50, e12334. [CrossRef] [PubMed]

13. Samsonraj, R.M.; Raghunath, M.; Nurcombe, V.; Hui, J.H.; van Wijnen, A.J.; Cool, S.M. Concise Review: Multifaceted Characterization of Human Mesenchymal Stem Cells for Use in Regenerative Medicine. Stem Cells Transl. Med. 2017, 6, 2173-2185. [CrossRef] [PubMed]

14. De Chiara, L.; Famulari, E.S.; Fagoonee, S.; van Daalen, S.K.M.; Buttiglieri, S.; Revelli, A.; Tolosano, E.; Silengo, L.; van Pelt, A.M.M.; Altruda, F. Characterization of Human Mesenchymal Stem Cells Isolated from the Testis. Stem Cells Int. 2018, 2018, 4910304. [CrossRef] [PubMed]

15. Mohamed-Ahmed, S.; Fristad, I.; Lie, S.A.; Suliman, S.; Mustafa, K.; Vindenes, H.; Idris, S.B. Adipose-derived and bone marrow mesenchymal stem cells: A donor-matched comparison. Stem Cell Res. Ther. 2018, 9, 168. [CrossRef] [PubMed]

16. Park, J.; Lee, J.H.; Yoon, B.S.; Jun, E.K.; Lee, G.; Kim, I.Y.; You, S. Additive effect of bFGF and selenium on expansion and paracrine action of human amniotic fluid-derived mesenchymal stem cells. Stem Cell Res. Ther. 2018, 9, 293. [CrossRef]

17. Ma, J.; Wu, J.; Han, L.; Jiang, X.; Yan, L.; Hao, J.; Wang, H. Comparative analysis of mesenchymal stem cells derived from amniotic membrane, umbilical cord, and chorionic plate under serum-free condition. Stem Cell Res. Ther. 2019, 10, 19. [CrossRef] [PubMed]

18. Shokri, M.R.; Bozorgmehr, M.; Ghanavatinejad, A.; Falak, R.; Aleahmad, M.; Kazemnejad, S.; Shokri, F.; Zarnani, A.H. Human menstrual blood-derived stromal/stem cells modulate functional features of natural killer cells. Sci. Rep. 2019, 9, 10007. [CrossRef]

19. Jiang, W.; Xu, J. Immune modulation by mesenchymal stem cells. Cell Prolif. 2020, 53, e12712. [CrossRef]

20. Hu, X.; Xu, Y.; Zhong, Z.; Wu, Y.; Zhao, J.; Wang, Y.; Cheng, H.; Kong, M.; Zhang, F.; Chen, Q.; et al. A Large-Scale Investigation of Hypoxia-Preconditioned Allogeneic Mesenchymal Stem Cells for Myocardial Repair in Nonhuman Primates: Paracrine Activity without Remuscularization. Circ. Res. 2016, 118, 970-983. [CrossRef]

21. Huang, B.; Cheng, X.; Wang, H.; Huang, W.; la Ga Hu, Z.; Wang, D.; Zhang, K.; Zhang, H.; Xue, Z.; Da, Y.; et al. Mesenchymal stem cells and their secreted molecules predominantly ameliorate fulminant hepatic failure and chronic liver fibrosis in mice respectively. J. Transl. Med. 2016, 14, 45. [CrossRef] 
22. Xiang, B.; Chen, L.; Wang, X.; Zhao, Y.; Wang, Y.; Xiang, C. Transplantation of Menstrual Blood-Derived Mesenchymal Stem Cells Promotes the Repair of LPS-Induced Acute Lung Injury. Int. J. Mol. Sci. 2017, 18, 689. [CrossRef] [PubMed]

23. Liu, Y.; Niu, R.; Li, W.; Lin, J.; Stamm, C.; Steinhoff, G.; Ma, N. Therapeutic potential of menstrual blood-derived endometrial stem cells in cardiac diseases. Cell Mol. Life Sci. 2019, 76, 1681-1695. [CrossRef] [PubMed]

24. Naji, A.; Favier, B.; Deschaseaux, F.; Rouas-Freiss, N.; Eitoku, M.; Suganuma, N. Mesenchymal stem/stromal cell function in modulating cell death. Stem Cell Res. Ther. 2019, 10, 56. [CrossRef] [PubMed]

25. Wang, Z.; Zheng, L.; Lian, C.; Qi, Y.; Li, W.; Wang, S. Human Umbilical Cord-Derived Mesenchymal Stem Cells Relieve Hind Limb Ischemia by Promoting Angiogenesis in Mice. Stem Cells Dev. 2019, 28, 1384-1397. [CrossRef]

26. Thomas, D.; Marsico, G.; Mohd Isa, I.L.; Thirumaran, A.; Chen, X.; Lukasz, B.; Fontana, G.; Rodriguez, B.; Marchetti-Deschmann, M.; O'Brien, T.; et al. Temporal changes guided by mesenchymal stem cells on a 3D microgel platform enhance angiogenesis in vivo at a low-cell dose. Proc. Natl. Acad. Sci. USA 2020, 117, 19033-19044. [CrossRef]

27. Nordberg, R.C.; Loboa, E.G. Our Fat Future: Translating Adipose Stem Cell Therapy. Stem Cells Transl. Med. 2015, 4, 974-979. [CrossRef]

28. Monsarrat, P.; Vergnes, J.N.; Planat-Bénard, V.; Ravaud, P.; Kémoun, P.; Sensebé, L.; Casteilla, L. An Innovative, Comprehensive Mapping and Multiscale Analysis of Registered Trials for Stem Cell-Based Regenerative Medicine. Stem Cells Transl. Med. 2016, 5, 826-835. [CrossRef]

29. Squillaro, T.; Peluso, G.; Galderisi, U. Clinical Trials With Mesenchymal Stem Cells: An Update. Cell Transplant. 2016, 25, 829-848. [CrossRef]

30. Kobayashi, K.; Suzuki, K. Mesenchymal Stem/Stromal Cell-Based Therapy for Heart Failure-What Is the Best Source? Circ. J. 2018, 82, 2222-2232. [CrossRef]

31. Ward, M.R.; Abadeh, A.; Connelly, K.A. Concise Review: Rational Use of Mesenchymal Stem Cells in the Treatment of Ischemic Heart Disease. Stem Cells Transl. Med. 2018, 7, 543-550. [CrossRef]

32. Cui, C.H.; Uyama, T.; Miyado, K.; Terai, M.; Kyo, S.; Kiyono, T.; Umezawa, A. Menstrual blood-derived cells confer human dystrophin expression in the murine model of Duchenne muscular dystrophy via cell fusion and myogenic transdifferentiation. Mol. Biol. Cell 2007, 18, 1586-1594. [CrossRef] [PubMed]

33. Meng, X.; Ichim, T.E.; Zhong, J.; Rogers, A.; Yin, Z.; Jackson, J.; Wang, H.; Ge, W.; Bogin, V.; Chan, K.W.; et al. Endometrial regenerative cells: A novel stem cell population. J. Transl. Med. 2007, 5, 57. [CrossRef] [PubMed]

34. Moll, G.; Drzeniek, N.; Kamhieh-Milz, J.; Geissler, S.; Reinke, P. Editorial comment: Variables affecting the presence of mesenchymal stromal cells in the peripheral blood and their relationship with apheresis product. Br. J. Haematol. 2020, 189, 593-596. [CrossRef] [PubMed]

35. Hida, N.; Nishiyama, N.; Miyoshi, S.; Kira, S.; Segawa, K.; Uyama, T.; Mori, T.; Miyado, K.; Ikegami, Y.; Cui, C.; et al. Novel cardiac precursor-like cells from human menstrual blood-derived mesenchymal cells. Stem Cells 2008, 26, 1695-1704. [CrossRef]

36. Patel, A.N.; Park, E.; Kuzman, M.; Benetti, F.; Silva, F.J.; Allickson, J.G. Multipotent menstrual blood stromal stem cells: Isolation, characterization, and differentiation. Cell Transplant. 2008, 17, 303-311. [CrossRef]

37. Asensi, K.D.; Fortunato, R.S.; dos Santos, D.S.; Pacheco, T.S.; de Rezende, D.F.; Rodrigues, D.C.; Mesquita, F.C.; Kasai-Brunswick, T.H.; de Carvalho, A.C.; Carvalho, D.P.; et al. Reprogramming to a pluripotent state modifies mesenchymal stem cell resistance to oxidative stress. J. Cell Mol. Med. 2014, 18, 824-831. [CrossRef]

38. Khanjani, S.; Khanmohammadi, M.; Zarnani, A.H.; Talebi, S.; Edalatkhah, H.; Eghtesad, S.; Nikokar, I.; Kazemnejad, S. Efficient generation of functional hepatocyte-like cells from menstrual blood-derived stem cells. J. Tissue Eng. Regen. Med. 2015, 9, E124-E134. [CrossRef]

39. Gargett, C.E.; Schwab, K.E.; Deane, J.A. Endometrial stem/progenitor cells: The first 10 years. Hum. Reprod. Update 2016, 22, 137-163. [CrossRef]

40. Cuenca, J.; Le-Gatt, A.; Castillo, V.; Belletti, J.; Díaz, M.; Kurte, G.M.; Gonzalez, P.L.; Alcayaga-Miranda, F.; Schuh, C.M.A.P.; Ezquer, F.; et al. The Reparative Abilities of Menstrual Stem Cells Modulate the Wound Matrix Signals and Improve Cutaneous Regeneration. Front. Physiol. 2018, 9, 464. [CrossRef]

41. Uzieliene, I.; Urbonaite, G.; Tachtamisevaite, Z.; Mobasheri, A.; Bernotiene, E. The Potential of Menstrual Blood-Derived Mesenchymal Stem Cells for Cartilage Repair and Regeneration: Novel Aspects. Stem Cells Int. 2018, 2018, 5748126. [CrossRef] 
42. Ren, H.; Sang, Y.; Zhang, F.; Liu, Z.; Qi, N.; Chen, Y. Comparative Analysis of Human Mesenchymal Stem Cells from Umbilical Cord, Dental Pulp, and Menstrual Blood as Sources for Cell Therapy. Stem Cells Int. 2016, 2016, 3516574. [CrossRef] [PubMed]

43. Sun, P.; Liu, J.; Li, W.; Xu, X.; Gu, X.; Li, H.; Han, H.; Du, C.; Wang, H. Human endometrial regenerative cells attenuate renal ischemia reperfusion injury in mice. J. Transl. Med. 2016, 14, 28. [CrossRef] [PubMed]

44. Chen, L.; Zhang, C.; Wang, X.; Xiang, B.; Wu, X.; Guo, Y.; Mou, X.; Yuan, L.; Chen, B.; Wang, J.; et al. Human Menstrual Blood-Derived Stem Cells Ameliorate Liver Fibrosis in Mice by Targeting Hepatic Stellate Cells via Paracrine Mediators. Stem Cells Transl. Med. 2017, 6, 272-284. [CrossRef] [PubMed]

45. Liu, Y.; Niu, R.; Yang, F.; Yan, Y.; Liang, S.; Sun, Y.; Shen, P.; Lin, J. Biological characteristics of human menstrual blood-derived endometrial stem cells. J. Cell Mol. Med. 2018, 22, 1627-1639. [CrossRef] [PubMed]

46. Khanmohammadi, M.; Khanjani, S.; Bakhtyari, M.S.; Zarnani, A.H.; Edalatkhah, H.; Akhondi, M.M.; Mirzadegan, E.; Kamali, K.; Alimoghadam, K.; Kazemnejad, S. Proliferation and chondrogenic differentiation potential of menstrual blood- and bone marrow-derived stem cells in two-dimensional culture. Int. J. Hematol. 2012, 95, 484-493. [CrossRef] [PubMed]

47. Montali, M.; Panvini, F.M.; Barachini, S.; Ronca, F.; Carnicelli, V.; Mazzoni, S.; Petrini, I.; Pacini, S. Human adult mesangiogenic progenitor cells reveal an early angiogenic potential, which is lost after mesengenic differentiation. Stem Cell Res. Ther. 2017, 8, 106. [CrossRef]

48. Conway, E.M.; Collen, D.; Carmeliet, P. Molecular mechanisms of blood vessel growth. Cardiovasc. Res. 2001, 49, 507-521. [CrossRef]

49. Potente, M.; Gerhardt, H.; Carmeliet, P. Basic and therapeutic aspects of angiogenesis. Cell 2011, 146, 873-887. [CrossRef]

50. Betz, C.; Lenard, A.; Belting, H.G.; Affolter, M. Cell behaviors and dynamics during angiogenesis. Development 2016, 143, 2249-2260. [CrossRef]

51. Brennen, W.N.; Nguyen, H.; Dalrymple, S.L.; Reppert-Gerber, S.; Kim, J.; Isaacs, J.T.; Hammers, H. Assessing angiogenic responses induced by primary human prostate stromal cells in a three-dimensional fibrin matrix assay. Oncotarget 2016, 7, 71298-71308. [CrossRef]

52. Gerhardt, H.; Golding, M.; Fruttiger, M.; Ruhrberg, C.; Lundkvist, A.; Abramsson, A.; Jeltsch, M.; Mitchell, C.; Alitalo, K.; Shima, D.; et al. VEGF guides angiogenic sprouting utilizing endothelial tip cell filopodia. J. Cell Biol. 2003, 161, 1163-1177. [CrossRef] [PubMed]

53. Nguyen, D.H.; Stapleton, S.C.; Yang, M.T.; Cha, S.S.; Choi, C.K.; Galie, P.A.; Chen, C.S. Biomimetic model to reconstitute angiogenic sprouting morphogenesis in vitro. Proc. Natl. Acad. Sci. USA 2013, 110, 6712-6717. [CrossRef] [PubMed]

54. Siekmann, A.F.; Affolter, M.; Belting, H.G. The tip cell concept 10 years after: New players tune in for a common theme. Exp. Cell Res. 2013, 319, 1255-1263. [CrossRef] [PubMed]

55. Palm, M.M.; Dallinga, M.G.; van Dijk, E.; Klaassen, I.; Schlingemann, R.O.; Merks, R.M. Computational Screening of Tip and Stalk Cell Behavior Proposes a Role for Apelin Signaling in Sprout Progression. PLoS ONE 2016, 11, e0159478. [CrossRef]

56. Lobov, I.B.; Renard, R.A.; Papadopoulos, N.; Gale, N.W.; Thurston, G.; Yancopoulos, G.D.; Wiegand, S.J. Delta-like ligand 4 (Dll4) is induced by VEGF as a negative regulator of angiogenic sprouting. Proc. Natl. Acad. Sci. USA 2007, 104, 3219-3224. [CrossRef]

57. Phng, L.K.; Gerhardt, H. Angiogenesis: A team effort coordinated by notch. Dev. Cell 2009, 16, 196-208. [CrossRef]

58. Eilken, H.M.; Adams, R.H. Dynamics of endothelial cell behavior in sprouting angiogenesis. Curr. Opin. Cell Biol. 2010, 22, 617-625. [CrossRef]

59. Cruys, B.; Wong, B.W.; Kuchnio, A.; Verdegem, D.; Cantelmo, A.R.; Conradi, L.C.; Vandekeere, S.; Bouché, A.; Cornelissen, I.; Vinckier, S.; et al. Glycolytic regulation of cell rearrangement in angiogenesis. Nat. Commun. 2016, 7, 12240. [CrossRef]

60. Murphy, K.C.; Fang, S.Y.; Leach, J.K. Human mesenchymal stem cell spheroids in fibrin hydrogels exhibit improved cell survival and potential for bone healing. Cell Tissue Res. 2014, 357, 91-99. [CrossRef]

61. Domnina, A.; Novikova, P.; Obidina, J.; Fridlyanskaya, I.; Alekseenko, L.; Kozhukharova, I.; Lyublinskaya, O.; Zenin, V.; Nikolsky, N. Human mesenchymal stem cells in spheroids improve fertility in model animals with damaged endometrium. Stem Cell Res. Ther. 2018, 9, 50. [CrossRef] 
62. Gonçalves, M.F.; Asensi, K.D.; Nascimento, A.L.L.; de Barros, J.H.O.; Santos, R.A.; Andrade, C.B.V.; Kasai-Brunswick, T.H.; Frajblat, M.; Ortiga-Carvalho, T.M.; Goldenberg, R.C.D.S. Human Menstrual Blood-Derived Mesenchymal Cells Improve Mouse Embryonic Development. Tissue Eng. Part A 2020. [CrossRef] [PubMed]

63. Liu, L.; Sun, Z.; Chen, B.; Han, Q.; Liao, L.; Jia, M.; Cao, Y.; Ma, J.; Sun, Q.; Guo, M.; et al. Ex vivo expansion and in vivo infusion of bone marrow-derived Flk-1+CD31-CD34- mesenchymal stem cells: Feasibility and safety from monkey to human. Stem Cells Dev. 2006, 15, 349-357. [CrossRef] [PubMed]

64. Shou, K.; Niu, Y.; Zheng, X.; Ma, Z.; Jian, C.; Qi, B.; Hu, X.; Yu, A. Enhancement of Bone-Marrow-Derived Mesenchymal Stem Cell Angiogenic Capacity by NPWT for a Combinatorial Therapy to Promote Wound Healing with Large Defect. Biomed. Res. Int. 2017, 2017, 7920265. [CrossRef] [PubMed]

65. Sheng, L.; Mao, X.; Yu, Q.; Yu, D. Effect of the PI3K/AKT signaling pathway on hypoxia-induced proliferation and differentiation of bone marrow-derived mesenchymal stem cells. Exp. Ther. Med. 2017, 13, 55-62. [CrossRef]

66. Wang, C.; Li, Y.; Yang, M.; Zou, Y.; Liu, H.; Liang, Z.; Yin, Y.; Niu, G.; Yan, Z.; Zhang, B. Efficient Differentiation of Bone Marrow Mesenchymal Stem Cells into Endothelial Cells in Vitro. Eur. J. Vasc. Endovasc. Surg. 2018, 55, 257-265. [CrossRef]

67. Chen, M.Y.; Lie, P.C.; Li, Z.L.; Wei, X. Endothelial differentiation of Wharton's jelly-derived mesenchymal stem cells in comparison with bone marrow-derived mesenchymal stem cells. Exp. Hematol. 2009, 37, 629-640. [CrossRef]

68. Qiu, X.; Zhang, Y.; Zhao, X.; Zhang, S.; Wu, J.; Guo, H.; Hu, Y. Enhancement of endothelial differentiation of adipose derived mesenchymal stem cells by a three-dimensional culture system of microwell. Biomaterials 2015, 53, 600-608. [CrossRef]

69. Arutyunyan, I.; Fatkhudinov, T.; Kananykhina, E.; Usman, N.; Elchaninov, A.; Makarov, A.; Bolshakova, G.; Goldshtein, D.; Sukhikh, G. Role of VEGF-A in angiogenesis promoted by umbilical cord-derived mesenchymal stromal/stem cells: In vitro study. Stem Cell Res. Ther. 2016, 7, 46. [CrossRef]

70. Shang, T.; Li, S.; Zhang, Y.; Lu, L.; Cui, L.; Guo, F.F. Hypoxia promotes differentiation of adipose-derived stem cells into endothelial cells through demethylation of ephrinB2. Stem Cell Res. Ther. 2019, 10, 133. [CrossRef]

71. Jervis, M.; Huaman, O.; Cahuascanco, B.; Bahamonde, J.; Cortez, J.; Arias, J.I.; Torres, C.G.; Peralta, O.A. Comparative analysis of in vitro proliferative, migratory and pro-angiogenic potentials of bovine fetal mesenchymal stem cells derived from bone marrow and adipose tissue. Vet. Res. Commun. 2019, 43, 165-178. [CrossRef]

72. Alcayaga-Miranda, F.; Cuenca, J.; Luz-Crawford, P.; Aguila-Díaz, C.; Fernandez, A.; Figueroa, F.E.; Khoury, M. Characterization of menstrual stem cells: Angiogenic effect, migration and hematopoietic stem cell support in comparison with bone marrow mesenchymal stem cells. Stem Cell Res. Ther. 2015, 6, 32. [CrossRef] [PubMed]

73. Chevallier, A.; Kieny, M.; Mauger, A. Limb-somite relationship: Effect of removal of somitic mesoderm on the wing musculature. J. Embryol. Exp. Morphol. 1978, 43, 263-278. [PubMed]

74. Christ, B.; Scaal, M. Formation and differentiation of avian somite derivatives. Adv. Exp. Med. Biol. 2008, 638, 1-41. [CrossRef] [PubMed]

75. Kazemnejad, S.; Zarnani, A.H.; Khanmohammadi, M.; Mobini, S. Chondrogenic differentiation of menstrual blood-derived stem cells on nanofibrous scaffolds. Methods Mol. Biol. 2013, 1058, 149-169. [CrossRef] [PubMed]

76. Nimmagadda, S.; Loganathan, P.G.; Wilting, J.; Christ, B.; Huang, R. Expression pattern of VEGFR-2 (Quek1) during quail development. Anat. Embryol. 2004, 208, 219-224. [CrossRef] [PubMed]

77. Kurz, H.; Gärtner, T.; Eggli, P.S.; Christ, B. First blood vessels in the avian neural tube are formed by a combination of dorsal angioblast immigration and ventral sprouting of endothelial cells. Dev. Biol. 1996, 173, 133-147. [CrossRef]

78. Cordeiro, I.R.; Lopes, D.V.; Abreu, J.G.; Carneiro, K.; Rossi, M.I.; Brito, J.M. Chick embryo xenograft model reveals a novel perineural niche for human adipose-derived stromal cells. Biol. Open 2015, 4, 1180-1193. [CrossRef]

79. Ebrahimi-Barough, S.; Kouchesfahani, H.M.; Ai, J.; Massumi, M. Differentiation of human endometrial stromal cells into oligodendrocyte progenitor cells (OPCs). J. Mol. NeuroSci. 2013, 51, 265-273. [CrossRef] 
80. Azedi, F.; Kazemnejad, S.; Zarnani, A.H.; Soleimani, M.; Shojaei, A.; Arasteh, S. Comparative capability of menstrual blood versus bone marrow derived stem cells in neural differentiation. Mol. Biol. Rep. 2017, 44, 169-182. [CrossRef]

81. Pouget, C.; Pottin, K.; Jaffredo, T. Sclerotomal origin of vascular smooth muscle cells and pericytes in the embryo. Dev. Biol. 2008, 315, 437-447. [CrossRef]

82. Shi, S.; Gronthos, S. Perivascular niche of postnatal mesenchymal stem cells in human bone marrow and dental pulp. J. Bone Miner. Res. 2003, 18, 696-704. [CrossRef] [PubMed]

83. Sacchetti, B.; Funari, A.; Michienzi, S.; Di Cesare, S.; Piersanti, S.; Saggio, I.; Tagliafico, E.; Ferrari, S.; Robey, P.G.; Riminucci, M.; et al. Self-renewing osteoprogenitors in bone marrow sinusoids can organize a hematopoietic microenvironment. Cell 2007, 131, 324-336. [CrossRef] [PubMed]

84. Crisan, M.; Yap, S.; Casteilla, L.; Chen, C.W.; Corselli, M.; Park, T.S.; Andriolo, G.; Sun, B.; Zheng, B.; Zhang, L.; et al. A perivascular origin for mesenchymal stem cells in multiple human organs. Cell Stem Cell 2008, 3, 301-313. [CrossRef] [PubMed]

85. Da Silva Meirelles, L.; Caplan, A.I.; Nardi, N.B. In search of the in vivo identity of mesenchymal stem cells. Stem Cells 2008, 26, 2287-2299. [CrossRef]

86. Paul, G.; Özen, I.; Christophersen, N.S.; Reinbothe, T.; Bengzon, J.; Visse, E.; Jansson, K.; Dannaeus, K.; Henriques-Oliveira, C.; Roybon, L.; et al. The adult human brain harbors multipotent perivascular mesenchymal stem cells. PLoS ONE 2012, 7, e35577. [CrossRef]

87. Lojewski, X.; Srimasorn, S.; Rauh, J.; Francke, S.; Wobus, M.; Taylor, V.; Araúzo-Bravo, M.J.; Hallmeyer-Elgner, S.; Kirsch, M.; Schwarz, S.; et al. Perivascular Mesenchymal Stem Cells From the Adult Human Brain Harbor No Instrinsic Neuroectodermal but High Mesodermal Differentiation Potential. Stem Cells Transl. Med. 2015, 4, 1223-1233. [CrossRef]

88. Schwab, K.E.; Gargett, C.E. Co-expression of two perivascular cell markers isolates mesenchymal stem-like cells from human endometrium. Hum. Reprod. 2007, 22, 2903-2911. [CrossRef]

89. Schüring, A.N.; Schulte, N.; Kelsch, R.; Röpke, A.; Kiesel, L.; Götte, M. Characterization of endometrial mesenchymal stem-like cells obtained by endometrial biopsy during routine diagnostics. Fertil. Steril. 2011, 95, 423-426. [CrossRef]

90. Masuda, H.; Anwar, S.S.; Bühring, H.J.; Rao, J.R.; Gargett, C.E. A novel marker of human endometrial mesenchymal stem-like cells. Cell Transplant. 2012, 21, 2201-2214. [CrossRef]

91. Spitzer, T.L.; Rojas, A.; Zelenko, Z.; Aghajanova, L.; Erikson, D.W.; Barragan, F.; Meyer, M.; Tamaresis, J.S.; Hamilton, A.E.; Irwin, J.C.; et al. Perivascular human endometrial mesenchymal stem cells express pathways relevant to self-renewal, lineage specification, and functional phenotype. Biol. Reprod. 2012, 86, 58. [CrossRef]

92. Liu, J.; Hao, H.; Xia, L.; Ti, D.; Huang, H.; Dong, L.; Tong, C.; Hou, Q.; Zhao, Y.; Liu, H.; et al. Hypoxia pretreatment of bone marrow mesenchymal stem cells facilitates angiogenesis by improving the function of endothelial cells in diabetic rats with lower ischemia. PLoS ONE 2015, 10, e0126715. [CrossRef] [PubMed]

93. Du, W.J.; Chi, Y.; Yang, Z.X.; Li, Z.J.; Cui, J.J.; Song, B.Q.; Li, X.; Yang, S.G.; Han, Z.B.; Han, Z.C. Heterogeneity of proangiogenic features in mesenchymal stem cells derived from bone marrow, adipose tissue, umbilical cord, and placenta. Stem Cell Res. Ther. 2016, 7, 163. [CrossRef] [PubMed]

94. Gharaei, M.A.; Xue, Y.; Mustafa, K.; Lie, S.A.; Fristad, I. Human dental pulp stromal cell conditioned medium alters endothelial cell behavior. Stem Cell Res. Ther. 2018, 9, 69. [CrossRef] [PubMed]

95. Miceli, V.; Pampalone, M.; Vella, S.; Carreca, A.P.; Amico, G.; Conaldi, P.G. Comparison of Immunosuppressive and Angiogenic Properties of Human Amnion-Derived Mesenchymal Stem Cells between 2D and 3D Culture Systems. Stem Cells Int. 2019, 2019, 7486279. [CrossRef]

96. Merckx, G.; Hosseinkhani, B.; Kuypers, S.; Deville, S.; Irobi, J.; Nelissen, I.; Michiels, L.; Lambrichts, I.; Bronckaers, A. Angiogenic Effects of Human Dental Pulp and Bone Marrow-Derived Mesenchymal Stromal Cells and their Extracellular Vesicles. Cells 2020, 9, 312. [CrossRef]

97. Hu, C.; Li, L. Preconditioning influences mesenchymal stem cell properties in vitro and in vivo. J. Cell Mol. Med. 2018, 22, 1428-1442. [CrossRef]

98. Teixeira, F.G.; Salgado, A.J. Mesenchymal stem cells secretome: Current trends and future challenges. Neural Regen. Res. 2020, 15, 75-77. [CrossRef]

99. Carmeliet, P.; De Smet, F.; Loges, S.; Mazzone, M. Branching morphogenesis and antiangiogenesis candidates: Tip cells lead the way. Nat. Rev. Clin. Oncol. 2009, 6, 315-326. [CrossRef] 
100. Jiang, Z.; Hu, X.; Yu, H.; Xu, Y.; Wang, L.; Chen, H.; Wu, R.; Zhang, Z.; Xiang, C.; Webster, K.A.; et al. Human endometrial stem cells confer enhanced myocardial salvage and regeneration by paracrine mechanisms. J. Cell Mol. Med. 2013, 17, 1247-1260. [CrossRef]

101. Campos de Carvalho, A.C.; Goldenberg, R.C.d.S. Stem cells: Tissue source and obtention protocols. In Mesenchymal Stem Cells: Concepts, Obtention Methods and Applications, 1st ed.; Atheneu: São Paulo, Brazil, 2012; Volume 1.

102. Brito, J.M.; Teillet, M.A.; Le Douarin, N.M. Induction of mirror-image supernumerary jaws in chicken mandibular mesenchyme by Sonic Hedgehog-producing cells. Development 2008, 135, 2311-2319. [CrossRef]

103. Hamburger, V.; Hamilton, H.L. A series of normal stages in the development of the chick embryo. J. Morphol. 1951, 88, 49-92. [CrossRef] [PubMed]

104. Steck, E.; Burkhardt, M.; Ehrlich, H.; Richter, W. Discrimination between cells of murine and human origin in xenotransplants by species specific genomic in situ hybridization. Xenotransplantation 2010, 17, 153-159. [CrossRef] [PubMed]

105. Culling, C.F.A. Handbook of Histopathological and Histochemical Techniques (Including Museum Techniques), 3rd ed.; Butterworths: Oxford, UK, 1974; p. 726.

Publisher's Note: MDPI stays neutral with regard to jurisdictional claims in published maps and institutional affiliations.

(C) 2020 by the authors. Licensee MDPI, Basel, Switzerland. This article is an open access article distributed under the terms and conditions of the Creative Commons Attribution (CC BY) license (http://creativecommons.org/licenses/by/4.0/). 